\title{
Multisociety Consensus Quality Improvement Revised Consensus Statement for Endovascular Therapy of Acute Ischemic Stroke
}

\begin{abstract}
From the American Association of Neurological Surgeons (AANS), American Society of Neuroradiology (ASNR), Cardiovascular and Interventional Radiology Society of Europe (CIRSE), Canadian Interventional Radiology Association (CIRA), Congress of Neurological Surgeons (CNS), European Society of Minimally Invasive Neurological Therapy (ESMINT), European Society of Neuroradiology (ESNR),

European Stroke Organization (ESO), Society for Cardiovascular Angiography and Interventions (SCAI), Society of Interventional Radiology (SIR), Society of Neurolnterventional Surgery (SNIS), and World Stroke Organization (WSO)

D. Sacks, B. Baxter, B.C.V. Campbell, J.S. Carpenter, C. Cognard, D. Dippel, M. Eesa, U. Fischer, K. Hausegger, J.A. Hirsch, M.S. Hussain, O. Jansen, M.V. Jayaraman, A.A. Khalessi, B.W. Kluck, S. Lavine, P.M. Meyers, S. Ramee, D.A. Rüfenacht, C.M. Schirmer, and D. Vorwerk

ABBREVIATIONS: ASPECTS = Alberta Stroke Program Early Computed Tomography Score; EVT = endovascular therapy; $\mathrm{mRS}=$ modified Rankin Scale; $\mathrm{mTICI}=$ modified thrombolysis in cerebral infarction; NIHSS = National Institutes of Health Stroke Scale; $\mathrm{QI}=$ quality improvement; SAH = subarachnoid hemorrhage; SICH = symptomatic intracranial hemorrhage; SITS-MOST = Safe Implementation of Thrombolysis in Stroke Monitoring Study; TICI = thrombolysis in cerebral infarction; $\mathrm{TIMI}=$ thrombolysis in myocardial infarction; TPA $=$ tissue plasminogen activator
\end{abstract}

E ndovascular therapy (EVT) for acute ischemic stroke in selected patients has recently been proved effective in several clinical trials, and the widespread adoption of thrombectomy into routine clinical practice has begun. However, these acute stroke services are resource-intensive, including advanced cerebral im-

From the Department of Interventional Radiology (D.S.), The Reading Hospital and Medical Center, West Reading, Pennsylvania; Department of Radiology (B.B.), Erlanger Medical Center, Chattanooga, Tennessee; Departments of Medicine and Neurology (B.C.V.C.), Melbourne Brain Centre at the Royal Melbourne Hospital, University of Melbourne, Parkville, Victoria, Australia; Department of Radiology (J.S.C.), West Virginia University, Morgantown, West Virginia; Department of Diagnostic and Therapeutic Neuroradiology (C.C.), Centre Hospitalier Universitaire de Toulouse, Hôpital Purpan, Toulouse, France; Department of Neurology (D.D.), Eras mus University Medical Center, Rotterdam, the Netherlands; Department of Radiology (M.E.), University of Calgary, Calgary, Alberta, Canada; Department of Neurology (U.F.), Inselspital-Universitätsspital Bern, Bern, Switzerland; Department of Radiology (K.H.), Klagenfurt State Hospital, Klagenfurt am Wörthersee, Austria; Neuroendovascular Program, Department of Radiology (J.A.H.), Massachusetts General Hospital, Boston, Massachusetts; Cerebrovascular Center, Neurological Institute (M.S.H.), Cleveland Clinic, Cleveland, Ohio; Department of Radiology and Neuroradiology (O.J.), Klinik für Radiologie und Neuroradiologie, Kiel, Germany; Departments of Diagnostic Imaging, Neurology, and Neurosurgery (M.V.J.), Warren Alpert School of Medicine at Brown University, Rhode Island Hospital, Providence Rhode Island; Department of Surgery (A.A.K.), University of California San Diego Health, San Diego, California; Interventional Cardiology (B.W.K.), Heart Care Group, Allentown, Pennsylvania; Departments of Neurological Surgery and Radiology (S.L.), Columbia University Medical Center/New York-Presbyterian Hospital, New York, New York; Departments of Radiology and Neurological Surgery (P.M.M.), Columbia University College of Physicians and Surgeons, New York, New York; Interventional Cardiology, Heart and Vascular Institute (S.R.), Ochsner Medical Center, New Orleans, Louisiana; Neuroradiology Division (D.A.R.), Swiss Neuro Institute-Clinic Hirslanden, Zürich, Switzerland; Department of Neurosurgery and Neuroscience Center (C.M.S.), Geisinger Health System, Wilkes-Barre, Pennsylvania; and Diagnostic and Interventional Radiology Institutes (D.V.), Klinikum Ingolstadt, Ingolstadt, Germany.

B.B. receives personal fees from Penumbra (Alameda, California), Medtronic (Dublin, Ireland), Stryker (Fremont, California), and Pulsar Vascular (Los Gatos, California) and has a patent (US8622992) issued to Advanced Catheter Therapies (Chattanooga, Tennessee). C.C. receives personal fees from MicroVention (Tokyo, Japan), Stryker, Medtronic, and Balt (Montmorency, France). D.D. receives grants from the Dutch Heart Foundation, AngioCare (Eemnes, the Netherlands), Medtronic/Covidien/ev3 (Dublin, Ireland), Medac/Lamepro (Breda, the Netherlands), Penumbra, Top Medical/Concentric (New York, New York), and Stryker. U.F. receives grants from the SWIFT DIRECT study and personal fees from Medtronic. J.A.H. receives personal fees from Medtronic, Globus (Audubon, Pennsylvania), and Codman Neuro (Raynham, Massachusetts). C.M.S. receives grants from the National Institutes of Health/National Institute of Neurological Disorders and Stroke, aging and highly trained multidisciplinary hospital teams rapidly responding to emergency activation. Despite the previous acceptance of intravenous fibrinolysis for acute ischemic stroke and the development of designated stroke centers, ${ }^{1}$ ischemic stroke remains a leading cause of adult death and disability. ${ }^{2}$ Many patients are not candidates for fibrinolysis, and intravenous therapy is relatively ineffective for severe strokes as a result of large cerebral artery occlusions. Moreover, it is uncertain if the benefits of endovascular stroke treatment in the trial setting can be generalized to clinical care provided by hospitals and teams of varying training, experience, and case volume. In other medical disciplines, rapid technologic advancement required guidelines to utilize these tools effectively and responsibly. ${ }^{3}$ Quality-improvement (QI) metrics for the outcomes of endovascular ischemic stroke treatment were published by a multisociety, multispecialty, international consensus group in 2013. ${ }^{4}$ These QI metrics have been accepted at a national level in Great Britain and Ireland ${ }^{5}$ but have yet to be included into stroke center accreditation requirements in the United States. Subsequent to the publication of the prior QI guidelines, eight randomized trials and several meta-analyses of EVT have been published. ${ }^{6-20}$ These randomized trials have established EVT as standard of care when available, ${ }^{5,21-23}$ and provide additional data on which to update the metrics and bench-

Medtronic, and Penumbra and personal fees from Toshiba (Otawara, Japan) and ExpertiCas (Southport, Connecticut) and is a stockholder in Neurotechnology Investors (Palo Alto, California). None of the other authors have identified a conflict of interest.

Table El is available online at www.jvir.org/cms/attachment/2119125784/ 2089482678/mmcl.xlsx.

This article was previously published in the Journal of Vascular and Interventional Radiology. The articles are identical except for minor stylistic and spelling differences in keeping with each journal's style. The JVIR article should be used when citing this article in a journal. @SIR, 2018 J Vasc Interv Radiol 2018; 29:441-53. http://doi.org/10.1016/j.jvir.2017.11.026

Please address correspondence to David Sacks, MD, Interventional Radiology, Reading Hospital, 6th and Spruce Streets, West Reading, PA 19612-6052; e-mail: david.sacks@towerhealth.org 


\begin{tabular}{ll}
\hline Score & \multicolumn{1}{c}{ Description } \\
\hline 0 & No perfusion, complete obstruction; no flow past occlusion of "major" vessel \\
1 & Perfusion past initial obstruction but limited distal branch filling with little/slow distal perfusion \\
$2 \mathrm{a}$ & Partial perfusion: $<50 \%$ of "major" vascular territory perfused (eg, filling and complete perfusion through one M2 division) \\
$2 \mathrm{~b}$ & Partial perfusion: $\geq 50 \%$ of major vascular territory is filled, but there is not complete and normal perfusion of entire territory \\
3 & Complete or full perfusion with filling of all distal branches \\
\hline
\end{tabular}

Note:- $\mathrm{mTICl}$ indicates modified thrombolysis in cerebral infarction.

marks of the previous paper. ${ }^{4}$ Therefore, it is now appropriate to revise the prior QI document based on new evidence.

Revision of this QI consensus statement remains focused on processes of care and patient outcomes. Other documents address standards for physician training ${ }^{24,25}$ and recommendations for patient selection and treatment methods. ${ }^{5,23}$ As in the previous guidelines, it is intended that these benchmarks be used in a quality-improvement program to assess and improve processes and outcomes in acute stroke revascularization. The benchmarks provide the consensus process and outcome consensus measures called for by the Stroke Treatment Academic Industry Roundtable (STAIR) IX for the next generation of endovascular trials. ${ }^{26}$ The benchmarks may also be suitable for accreditation of stroke intervention programs. Most of the metrics apply to the role of the interventional physician, regardless of specialty or particular board certification, but comprehensive stroke care requires a broad multidisciplinary process involving care that ranges from emergency dispatch of paramedics through acute hospital care and posttreatment subacute rehabilitation. Therefore, although it is not the intention of this document to assess in detail the quality of facilities, some of the metrics also apply to institutional policies and procedures for stroke care.

\section{MATERIALS AND METHODS}

A literature search was conducted by using Ovid and EMBASE from 2012 (from the last date of the literature search for the first publication of these metrics) ${ }^{4}$ to October 2015 by using article titles that included the following: (acute ischemic stroke OR cerebrovascular accident OR stroke) AND (intra-arterial OR intraarterial OR endovascular OR angioplasty OR stent OR stent retriever OR mechanical thrombectomy OR thrombolysis OR tissue plasminogen activator [TPA] OR TPA OR urokinase OR streptokinase OOR TPA OR urokinaseR alteplase OR tenecteplase). Additional articles were then solicited from writing group members. An evidence table (Table E1, available on-line at www.jvir.org/cms/attachment/2119125784/2089482678/ mmcl.xlsx) was constructed by using articles that were randomized controlled trials, registries, or case series of at least 100 patients, and some case series of less than 100 patients were included if the series provided uniquely useful data. From the evidence table, metrics were chosen that were believed to be important markers of quality of care. Thresholds for metrics were then chosen by consensus of the writing group based on review of the evidence table. Consensus was defined as $80 \%$ of the writing group. If consensus was not achieved during discussion, a modified Delphi process was used to obtain consensus. ${ }^{27}$ If consensus was not achieved after the modified Delphi process, a threshold was not chosen. The evidence table was then updated by using the same search terms in February 2017 at the time of completion of the draft of the document to allow updating of the metrics if appropriate.

Standards for developing clinical practice guidelines were reviewed..$^{28}$ It was determined that most of these standards were not applicable for this document that updates quality benchmarks for processes and outcomes of care rather than creating recommendations for types of patient care. For this reason, this revision has been changed to a consensus statement rather than a guideline.

\section{DEFINITIONS}

Measures and metrics will depend on the definition of a good outcome or a complication and the time at which patients are assessed for these outcomes, as many patients show gradual improvement following an ischemic stroke. Numerous trials have used varying definitions for similar concepts. The definitions used in this document were derived from review of these trials and then consensus of the writing group.

Ischemic Central Nervous System Infarction. A uniformly accepted simple definition of central nervous system infarction remains elusive. A successful multidisciplinary attempt arrived at a definition as follows ${ }^{29}$ :

Central nervous system infarction is defined as brain, spinal cord, or retinal cell death due to ischemia, based on:

1. Pathological, imaging, or other objective evidence of cerebral, spinal cord, or retinal focal ischemic injury in a defined vascular distribution; or

2. Clinical evidence of cerebral, spinal cord, or retinal focal ischemic injury based on symptoms persisting at least 24 hours or until death, and other etiologies excluded.

Door-to-Event Time. The term "door" is used to determine the time of onset of medical care, as in "door to time of CT imaging." It is defined as the time of arrival in the emergency department for an outpatient or the time first discovered to have a stroke for an inpatient. When patients are transferred, "door" refers to the arrival (ie, registration) time at the receiving facility.

Time to Thrombus. Time to thrombus is considered to represent the start of endovascular lytic infusion or first placement of a mechanical device in the target vessel.

Successful Revascularization. Successful revascularization is considered to represent modified thrombolysis in cerebral infarction $(\mathrm{mTICI})^{30,31}$ grade $2 \mathrm{~b}$ or 3 flow through the previously occluded vessel segment (Table 1).

Symptomatic Intracranial Hemorrhage. Symptomatic intracranial hemorrhage (SICH) is a parenchymal hematoma type II (per the Safe Implementation of Thrombolysis in Stroke Monitoring Study [SITS-MOST] definition) $)^{32}$ or subarachnoid hemorrhage 


\begin{tabular}{ll}
\hline Score & Description \\
\hline 0 & No symptoms \\
1 & Slight disability: able to look after own affairs without assistance but unable to carry out all previous activities \\
2 & Moderate disability: requires some help but able to walk unassisted \\
3 & Moderately severe disability: unable to attend to own bodily needs without assistance and unable to walk unassisted \\
4 & Severe disability: requires constant nursing care and attention, bedridden, incontinent \\
5 & Dead
\end{tabular}

Note:- mRS indicates modified Rankin Scale

(SAH) with neurologic deterioration leading to an increase in National Institutes of Health Stroke Scale (NIHSS) score $>4$ or leading to death within 36 hours of treatment. Because of the risk of vessel perforation during endovascular procedures, SAH has been added as a cause of intracranial hemorrhage to the SITSMOST SICH definition. ${ }^{33}$

This definition is similar to that used in the recent randomized trials of EVT. ${ }^{7,11,15}$ Several of the authors of those trials have joined others in proposing a new definition of SICH. ${ }^{34}$ These new definitions have not yet been validated on a larger scale, adopted in stroke trials, or applied to the outcomes of the recent randomized trials. Therefore, the original definition of $\mathrm{SICH}$ is maintained in the present revision of the consensus statement and modified to include any intracranial hemorrhage associated with a decrease in NIHSS score $>4$ or death within 24 hours of the end of the revascularization procedure. ${ }^{20}$

Good Clinical Outcome. A good clinical outcome is a measure of neurologic functional with a score of $0-2$ on the modified Rankin Scale (mRS; Table 2$)^{35}$ assessed 90 days after treatment. This does not exclude clinically significant benefit in patients in whom an mRS score of 2 is not achieved.

\section{INDICATIONS AND CONTRAINDICATIONS}

EVT for acute ischemic stroke with large vessel occlusion is established in guidelines as the standard of care. ${ }^{22,36}$ If the patient is also eligible for intravenous TPA, this drug should be administered as a "bridging" strategy in parallel without delaying thrombectomy. Waiting to assess "response" to TPA is strongly discouraged, ${ }^{22}$ as clinical improvement may not indicate recanalization. The rate of TPA-induced recanalization before thrombectomy (performed without delay) was $<10 \%$ in recent randomized trials. ${ }^{11,13,20}$ Proceeding directly to thrombectomy (ie, direct thrombectomy) should be performed in appropriate candidates with a contraindication to TPA, including risk of hemorrhage or when $>4.5$ hours have elapsed since stroke onset.

Indications and contraindications for EVT are based on subgroup analyses of randomized trials and case series. Clinical trials tend to have more restrictive criteria, whereas case series represent more of a "real-world" experience. Potential selection criteria are based on stroke severity, time (ie, duration of symptoms), imaging, clot location, age, and comorbidities.

Stroke Severity. Clinical trials have set variable NIHSS score limits for eligibility, often requiring $\geq 6,8$, or 10 points. The Multicenter Randomized Clinical Trial of Endovascular Treatment for Acute Ischemic Stroke in the Netherlands (MR CLEAN) trial had a minimum NIHSS score of 2 and Extending the Time for Thrombolysis in Emergency Neurologic Deficits-Intra-Arte- rial (EXTEND-IA) had no NIHSS score limits, but, given the requirement for large vessel occlusion, few patients with NIHSS scores $<6$ were enrolled. ${ }^{37}$ Individual patient data meta-analysis of five positive randomized trials ${ }^{14}$ demonstrated highly consistent treatment effects across the NIHSS score spectrum, at least for NIHSS scores $\geq 6$. Data from observational studies have demonstrated an important incidence of large vessel occlusion in patients with clinically mild stroke and a propensity for these patients to later experience neurologic deterioration. ${ }^{38}$ The risk/ benefit in patients with low NIHSS scores therefore needs to be carefully considered, and future studies have to address whether endovascular procedures are beneficial in patients with mild symptoms and proximal vessel occlusion. There are no data supporting an upper limit on stroke severity.

Time. Most trials of intra-arterial lytic agents and mechanical revascularization devices have historically required start of treatment within 6 or 8 hours ${ }^{39-42}$ for anterior-circulation strokes. The strongest evidence for EVT is for treatment commenced within 6 hours. ${ }^{14,43}$ More rapid time to reperfusion has been linked to improved clinical outcomes and is therefore an important consideration in patient selection. ${ }^{43-45} \mathrm{~A}$ few patients in recent trials were treated at 6-8 hours in the Randomized Trial of Revascularization with Solitaire FR Device versus Best Medical Therapy in the Treatment of Acute Stroke Due to Anterior Circulation Large Vessel Occlusion Presenting within Eight Hours of Symptom Onset (REVASCAT) trial $^{15}$ and at 6-12 hours in the Endovascular Treatment for Small Core and Anterior Circulation Proximal Occlusion with Emphasis on Minimizing CT to Recanalization Times (ESCAPE) trial. ${ }^{13}$ Individual patient data meta-analysis suggests significant benefit to at least 7 hours, 18 minutes. ${ }^{46} \mathrm{Ob}$ servational studies have suggested that patients presenting at later time points with favorable imaging findings still benefit from reperfusion, ${ }^{47}$ and this was confirmed in the DWI or CTP Assessment with Clinical Mismatch in the Triage of Wake-Up and Late Presenting Strokes Undergoing Neurointervention with Trevo (DAWN) trial, ${ }^{48}$ which used clinical-core mismatch criteria to select patients 6-24 hours after the "last known well" time. In the DAWN trial, ${ }^{48}$ independent functional outcome occurred in $48.6 \%$ of patients who underwent endovascular treatment versus $13.1 \%$ of control patients $(P<.0001)$ with similar revascularization success as $0-6$-hour thrombectomy trials and no variation in treatment effect between the 6- to 12-hour and 12- to 24-hour treatment windows. Other randomized trials in extended time windows are ongoing. ${ }^{49,50}$ Vertebrobasilar occlusions have been treated at extended times, sometimes more than 24-48 hours after symptom onset. ${ }^{51,52}$ This is partly because of the traditional definition of onset as the last known well time. Patients with basi- 
lar artery occlusion may have prodromal mild symptoms in $60 \%$ of cases before the development of severe deficits. ${ }^{53}$ The Basilar Artery International Cooperation Study (BASICS) registry ${ }^{53}$ advocated using time of severe deficit (ie, likely moment of occlusion) and found that good outcome with reperfusion beyond 9 hours of that time was extraordinarily rare. ${ }^{53}$ Randomized trials in patients with basilar artery occlusion are ongoing. ${ }^{54,55}$

Imaging. Noncontrast CT has been an essential component of patient selection in randomized trials of intravenous and endovascular revascularization for treatment of acute stroke. ${ }^{1,7,11,13,15,20,39-41,56}$ Absolute noncontrast CT contraindications to endovascular treatment are similar to those for intravenous thrombolytic agents and include the presence of acute intracranial hemorrhage or a significant established infarct. $^{1}$

Infarct size can be approximated on noncontrast CT by using the Alberta Stroke Program Early CT Score (ASPECTS). ${ }^{57,58}$ However, the score is not closely related to infarct volume or functional eloquence and has variable interrater agreement, particularly early after stroke onset. In recent randomized trials, there was clear benefit in patients with ASPECTS 6-8 and 9/10. Relatively few patients with ASPECTS 0-5 were included in the trials. The benefit in this group appeared to be of lesser magnitude, but a clinically meaningful benefit could not be excluded. ${ }^{14}$ Patients with ASPECTS 3-5 will be evaluated in a randomized trial. ${ }^{59}$

The hyperdense middle cerebral artery sign can alert clinicians to the presence of a large vessel occlusion. This sign has a high degree of sensitivity if thin $(\sim 1-\mathrm{mm})$ slices are reconstructed and good specificity if clearly asymmetric compared with the contralateral artery. ${ }^{60}$ Clot length on noncontrast CT of more than 8 $\mathrm{mm}$ has been associated with lower recanalization rates after intravenous TPA, ${ }^{61}$ but this is not absolute, ${ }^{62}$ and none of the positive randomized trials considered clot length in determining eligibility. The Randomized, Concurrent Controlled Trial to Assess the Penumbra System's Safety and Effectiveness in the Treatment of Acute Stroke (THERAPY) trial that used this criterion was neutral. ${ }^{18}$ There is evidence that occult anterograde flow can be associated with TPA-induced recanalization even in the presence of a long thrombus. ${ }^{63}$

The target vessel occlusion should be established by using noninvasive angiography (CT or MR imaging), as practiced in all the positive randomized trials. This also provides information on proximal arterial pathology and catheter access. CT angiography has also been used to grade the quality of collateral flow. However, there is potential for standard single early-phase acquisitions to underestimate late-arriving collateral flow and therefore exclude patients who may benefit. Dynamic angiography derived from CT perfusion or multiphase CT angiography acquisitions avoids this pitfall. $^{64}$

Many centers use CT perfusion to improve diagnostic sensitivity and provide an estimate of tissue viability, which is closely related to the quality of collateral blood flow. A large volume of ischemic core (eg, $>70 \mathrm{~mL}$ ) on CT perfusion is certainly associated with a worse prognosis, but whether this alters treatment effect within 6 hours of stroke onset is yet to be clarified. Some case series have suggested a benefit of reperfusion even in patients with a large ischemic core $>100 \mathrm{~mL} \cdot{ }^{65}$ Analysis of the MR CLEAN trial did not reveal treatment effect heterogeneity between cases of $<70$ and $>70-\mathrm{mL}$ core, although the absolute probability of independent functional outcome in those with a core $>70 \mathrm{~mL}$ was only $8 \% .{ }^{66}$ Rather than excluding patients from treatment as a result of a large ischemic core, the presence of favorable imaging may be useful in deciding to pursue treatment in patients with otherwise less favorable clinical characteristics. Estimation of ischemic core volume by using CT perfusion combined with age and NIHSS score in clinical-core mismatch was shown to identify patients who benefit from thrombectomy in the extended time window of 6-24 hours in the DAWN trial. ${ }^{48}$

MR imaging with diffusion imaging, with or without perfusion imaging, is increasingly used in some centers. There are some logistic challenges of safety screening and rapid access to MR scanners that have to be overcome to avoid relevant delays in treatment. However, in the high-performing centers in the Solitaire With the Intention For Thrombectomy as PRIMary Endovascular treatment (SWIFT PRIME trial) ${ }^{44}$ there was no significant difference in arrival to randomization time according to image technique (ie, CT versus MR imaging), suggesting that MR-related delay is not inevitable. Uncertainties regarding whether core volume is truly treatment effect-modifying or simply prognostic apply, as discussed with CT perfusion. ${ }^{65}$ It is also important to note that measured perfusion lesion volumes vary between processing software programs and the thresholds used to estimate ischemic core may vary with time. ${ }^{67}$

Clot Location. The randomized trials demonstrated clear benefit in internal carotid artery terminus and M1 (ie, first segment of middle cerebral artery) occlusion, with or without tandem occlusion in the cervical carotid artery. ${ }^{10,14}$ Arterial occlusions arising more proximally are associated with poorer outcomes. Most notably, "T-lesions" have the poorest outcomes among anteriorcirculation strokes. ${ }^{68,69}$ Proximal M1 occlusions have worse outcomes than distal M1 occlusions as a result of occlusion of lenticulostriate arteries and basal ganglia infarction, with an increased risk of reperfusion hemorrhage. ${ }^{70}$ More distal M2 occlusions were less common among trial patients, and a clear benefit was not demonstrated, although there was no significant heterogeneity in treatment effect observed. Many patients with M2 occlusions were assessed as having M1 occlusions at the site and reclassified as having M2 occlusions by the core laboratory, leading to a predominance of larger, more proximal occlusions. Some case-control studies have suggested that benefit persists in M2 occlusions, with similar safety as M1 occlusions. ${ }^{71}$ Basilar artery occlusion was not included in the recent trials, in some cases because of perceived lack of equipoise and in others because of concerns regarding excessive heterogeneity. The BASICS trial ${ }^{54}$ is ongoing, but many sites regard the dismal prognosis if untreated and the clear improvement associated with recanalization as sufficient grounds to treat. EVT for occlusions in the anterior cerebral artery, M3/4 segments, and posterior cerebral artery has not been systematically studied. More distal vessels are smaller and more tortuous, which potentially increases procedural risk, and the smaller territory at risk and increased efficacy of TPA reduces the benefit. Further device development may alter this balance in the future. 
Age. Although increased age is associated with a worse prognosis after stroke in general, the recent trials have clearly demonstrated a treatment effect in patients aged $>80$ years of at least the same magnitude as in younger patients. Indeed, there is a significant mortality benefit in elderly patients, with $20 \%$ absolute risk reduction (number needed to treat $=5$ ).${ }^{10,14}$ Importantly, the trials included only patients with independent premorbid function, regardless of age, and the potential quality-of-life benefit for patients with significant comorbidities needs to be weighed in clinical practice. Prestroke dementia before endovascular reperfusion has been linked with a low probability of achieving a good clinical outcome. ${ }^{72}$ Some trials have therefore excluded patients aged $>80$ years. ${ }^{73}$ Older patients may also have tortuous arterial access, which can complicate the procedure.

Medical Comorbidities. Most contraindications to intravenous thrombolysis do not apply to EVT. Overall, mechanical thrombectomy (with or without intravenous TPA) has a similar risk of SICH compared with TPA alone. ${ }^{10,14}$ There are relatively limited data on the safety of EVT in patients with markedly abnormal coagulation (eg, International Normalized Ratio $>3.0$ or current use of novel or direct oral anticoagulant agents), and risks and benefits need to be considered on an individual basis.

The criteria chosen to select patients for treatment will affect outcomes. Patients at higher risk are more likely to do poorly with or without treatment, but selection of only patients at low risk will deny clinical benefit to a large number of severely ill patients. Because published selection criteria vary, there is no single "correct" list of inclusion and exclusion criteria. The American Heart Association has published class I recommendations for EVT patient selection, ${ }^{22}$ but $40 \%-50 \%$ of patients are now being treated outside of these class I recommendations. ${ }^{74,75}$ Based on published data and the desired ratio of benefit to risk, each institution will need to create and follow its own indications and contraindications.

Metric 1: At least $90 \%$ of patients who meet the institutional selection criteria (ie, indications/contraindications) should be treated with endovascular therapy.

\section{PROCESS AND OUTCOMES METRICS}

In general, previously published endovascular stroke therapy metrics $^{76}$ were designed to measure aggregate performance of hospital or clinical outcomes. They were neither designed nor intended to define individual physician performance. In contrast, this document provides requirements for performance criteria for the individual practitioner and the facility. The purpose of these metrics is to define the minimum standards for EVT in acute ischemic stroke patients. It is recognized that a concerted team effort is required to ensure efficient workflow, timely EVT, and safe, effective care.

The recent endovascular trials have reiterated the importance of appropriate patient selection and procedural performance such as timely and more complete revascularization to improve the likelihood of achieving a good clinical outcome. This paradigm is based on selecting patients with potentially salvageable ischemic penumbra. A noncontrast head CT/MR study and vascular imaging such as CT/MR angiography will demonstrate areas of estab- lished infarct and presence of a proximal large vessel occlusion, respectively, and provide vital information to select patients for endovascular therapy.

\section{Data Collection}

From a quality-assurance perspective, endovascular therapy for acute ischemic stroke differs slightly from other areas in which quality initiatives, morbidity, and mortality discussions focus on specific events in which errors in care or complications occurred. The measure of benefit from endovascular stroke therapy is not based on single or isolated cases, but rather is expressed as a percentage of aggregated patients treated who can function independently at 3 months. This has also been measured by using shift analysis in the recent endovascular trials. ${ }^{77}$ As demonstrated in those trials, clinical benefit from EVT is dependent on delivery of high-quality care in a timely manner at the institutional level by a dedicated team.

As such, performance metrics from large aggregates of patients treated by endovascular means are compared versus performance standards in clinical trials in which benefits were demonstrated, recognizing that patients may be treated outside trial inclusion criteria on a case-by-case basis. This requires all patients' procedural, process, and clinical outcomes to be entered into a data base, trial, or registry. ${ }^{24,76,78-80}$ Without the denominator of "all patients," measures of success and percentage descriptors are meaningless. These data allow comparison of metrics against benchmarks for individual operator performance, risk-adjusted clinical outcomes, and individual and institutional process measures.

As stated in a prior document concerning Comprehensive Stroke Centers, ${ }^{76}$ it is advantageous to collect data in a standardized fashion to avoid redundant efforts. Data collection tools such as multicenter registries will serve as useful benchmarks and will facilitate an ongoing process of constant evaluation. Multicenter registries are recommended over institutional registries because of the ability to serve as a benchmark against other institutions. There are numerous examples of such data-collection tools for treatment of acute ischemic stroke. ${ }^{78,80-82}$ A recent publication looking at trends in endovascular therapy and clinical outcomes within the Get With The Guidelines-Stroke registry ${ }^{83}$ demonstrates the utility of strict data collection within well-maintained nationwide data base systems.

Data collection for EVT is closely tied in with the process already in place for patients who are eligible for intravenous thrombolytic therapy and starts with documentation of time of onset and the time the patient arrives at the "door." This could mean ( $i$ ) the door of a primary stroke center, where data collection should ideally start, or, (ii) in cases being transferred to an endovascular center, the time of registration at the center that receives the patient. The detailed time metrics will be discussed in the next section. Data collection, especially time points, should be as inclusive as possible, with subsequent metrics being reported by combining multiple elements. The mandatory threshold for collection of the minimum defined elements is $100 \%$.

Data concerning demographic characteristics are used to identify various patient subgroups, whereas other data points are pertinent for risk adjustment and are necessary for evaluation of pro- 
cedural and clinical outcomes. These would include factors specific to the individual case, such as location of occlusion and time from onset, as well as demographic factors specific to patient subgroups, such as age, race, and sex. Ancillary data such as prognostic factors pertaining to comorbidity, stroke severity, and imaging parameters may help in risk- and severity-adjusted analysis to adjust for variability in case mix. Collection of these data points is necessary for an appropriate evaluation of patient risk factors and also for study of institutional factors that could influence overall patient outcomes and have a bearing on evaluation of operator performance.

At a minimum, these data should include age, sex, premorbid mRS score, NIHSS score, location of occlusion, various time points and intervals described in the subsequent sections, blood pressure, blood glucose level at presentation, and presence of atrial fibrillation. Specific data-collection metrics for EVT have already been included in national guidelines. ${ }^{22,23,36}$ Other data elements may be helpful and may become evident with further research, such as radiation exposure and contrast agent dose.

Metric 2: $100 \%$ of patients have the required minimum process and outcomes data entered into an institutional or national data base, trial, or registry.

\section{Time Intervals}

Emergency endovascular stroke treatment is one of the most complex multidisciplinary functions a medical institution chooses to undertake. Reperfusion treatment (intravenous or endovascular) achieved within the shortest period of time is widely accepted as a prerequisite for optimal clinical outcomes. ${ }^{45,84,85}$

Subgroup analyses from several trials $s^{43,86,87}$ have shown that treatment delays resulted in significant decrease in the likelihood of a good outcome of endovascular stroke therapy. Analysis of the pooled data of 5 endovascular trials ${ }^{46}$ confirmed this: every 1-hour delay in time from onset to arterial puncture results in a $5.3 \%$ shift in the direction of more disability on the mRS.

There are many steps from stroke onset to completion of treatment, and optimal and timely execution of each of these steps is necessary to achieve the stated goal. Numerous opportunities exist to minimize the time needed for each step from the time of the acute stroke to patient arrival to the hospital and then until reperfusion is achieved.

Process improvement for emergency stroke treatment should be an ongoing component of all stroke systems of care and should focus on all the tasks and activities in this complex sequence of events. These data are then used for quality assessment/assurance and process improvement and therefore directly relate to the eventual clinical outcome of the patients being treated by the team. To judge satisfaction of these performance goals in regard to expeditious delivery of care, time points and intervals are the units of measurement.

At a minimum, the time points and intervals specified in this document should be tracked in all cases. Institutions may choose to measure additional time points. The more time points that are recorded, the more exactly deficiencies might be identified; however, this may prove onerous to document from a resource perspective. For instance, delays in obtaining a CT scan may result from delay in ordering the study, delay in response by CT staff (eg, multiple other procedures being requested at the same time), or delay related to transportation.

Acknowledgment of the critical importance of time to reperfusion for obtaining favorable outcomes in myocardial reperfusion treatments has led to the formation of initiatives such as "Door to Balloon: An Alliance of Quality" for patients with STsegment elevation myocardial infarction. The key was achievement of a door-to-balloon time of $<90$ minutes for at least $75 \%$ of patients presenting directly to the treating hospital by using various strategies identified through research, resulting in dramatic reductions in times. ${ }^{88,89}$

The impressive results in shortening the time to myocardial reperfusion for acute myocardial infarction obtained by such initiatives provided an impetus for launching similar initiatives related to intravenous TPA for stroke. ${ }^{90}$ The Joint Commission has set a more ambitious goal of $80 \%$ of patients treated within 1 hour for primary stroke centers. ${ }^{91}$ The experience in reducing door-toneedle times reported by the group from Helsinki ${ }^{92}$ suggests that, with simple strategies, median door-to-needle times of $30 \mathrm{~min}$ utes or even less can be achieved. Because of the need for neurologic assessment and imaging in addition to the emergency medicine and interventional components, acute stroke patients referred for EVT require more time for initiation of treatment than patients with ST-segment elevation myocardial infarction. Although rapid-response mechanisms aiming to result in initiation of revascularization therapies within the minimum amount of time can be modeled according to the myocardial infarction experience, it should be recognized that acute stroke treatment, especially EVT, requires a far more complex infrastructure. Notwithstanding that, it is clear that, similar to the cardiology model, major improvements in door-to-treatment time need to take place to increase the proportion of favorable outcomes for patients treated with EVT for acute stroke. ${ }^{93}$

Since the early years of endovascular stroke treatment, various time metrics have been reported, with a trend toward overall improvement in times. These were initially reported on the basis of case series, ${ }^{94,95}$ with newer metrics from registries, ${ }^{96,97}$ earlier device trials, ${ }^{98,99}$ and recent randomized controlled trials. ${ }^{10}$ These reports focused on median onset-to-groin puncture times ranging from 200 minutes in the latest randomized trials ${ }^{10}$ to 277 minutes in registry data. ${ }^{97}$ Recent trial data ${ }^{10}$ have also reported various components of these times, breaking them down into intervals that include patient arrival times and imaging times. In the ESCAPE trial, ${ }^{13}$ the authors reported a median time from imaging to arterial puncture of 51 minutes and a median time from imaging to reperfusion of 84 minutes. The median imagingto-puncture time in the SWIFT PRIME trial ${ }^{20}$ was 57 minutes. The Highly Effective Reperfusion evaluated in Multiple Endovascular Stroke trials (HERMES) meta-analysis of treatment times from five recent large endovascular trials ${ }^{46}$ reported better clinical outcomes with faster treatment times, with median door-to-imaging time of 19 minutes, imaging-to-puncture time of 76 minutes, and puncture-to-reperfusion time of 44 minutes in the entire cohort.

The endovascular trials represent optimal results based on study site and patient selection. Many of the endovascular trials included only study sites with a proved ability to respond rapidly, 
excluded patients with carotid dissections or internal carotid artery-origin occlusions, and excluded patients who could not be treated rapidly. However, the reported times in recent trials did include time taken for patient randomization. These rapid responses have not been uniformly achieved in other trials, registries, or case series. ${ }^{18,100-102}$ Nevertheless, the time intervals in this consensus statement are intended to be achievable with good practice as centers become proficient at routinely performing endovascular therapies, and provide a benchmark for QI in current clinical practice. Moreover, many of the conditions and findings that, in the past, could have complicated decision-making, such as older age, extracranial carotid obstruction, vessel tortuosity, requirement for penumbral imaging, and requirement for general anesthesia, did not negatively influence treatment effect and should not delay the decision for treatment. The treatment of more complex cases than were included in the trials may prolong treatment times but should not prolong the time to arterial puncture.

As a general approach to setting metrics for care processes, we used data from the HERMES collaboration. ${ }^{46}$ The 75 th-percentile times (ie, slowest quartile) are considered minimum benchmarks, and the 25th-percentile times (ie, fastest quartile) from that study are considered achievable by the best centers with high volumes and good resource infrastructure. The metrics are intended to be used for measurements such that centers will progressively become faster and improve times from minimum acceptable to ideal.

The times reported in the following sections apply to anterior circulation occlusions, as vertebrobasilar occlusions were excluded in the recent randomized trials. These metrics should be applicable regardless of the time of the day and regardless of whether the patient presents on a weekday versus a weekend. ${ }^{103}$ These metrics represent maximum recommended times. Because of ample evidence that, the shorter the time to reperfusion, the higher the likelihood of a favorable outcome, all centers should strive to initiate endovascular therapy within the shortest possible time frame. Although intravenous TPA administration should not represent a justification for excessive delays in initiation of endovascular therapy, it is acknowledged that intravenous thrombolysis may be associated with some delays in initiation of endovascular therapy.

Door to Imaging. Most hospitals will use CT-based imaging, but some hospital protocols may use MR imaging as the first imaging study. The use of CT angiography or MR angiography for vascular imaging is considered the standard of care for endovascular treatment based on recent trials and should be incorporated into the imaging protocol. Indeed, previously published guidelines on imaging in acute stroke patients ${ }^{104}$ recommend that noninvasive vascular imaging be routinely performed, and it is recognized that the use of advanced multimodal imaging does not delay treatment times. ${ }^{105}$ Regardless of the choice of technique based on institutional preferences, imaging should be started as quickly as feasible. Because of the difficulty in defining exactly when an order might have been entered in the system, this document is in agreement with the American Stroke Association recommendations that these time intervals be measured from arrival to start of imaging, which will also include vascular imaging. Interpretation of imaging is done in parallel and usually at the scanner by the treat- ing team, and the time needed to interpret the scans and make a decision will be part of the overall time from the start of imaging to arterial puncture. In the HERMES meta-analysis, ${ }^{46}$ the fastest $25 \%$ of cases had imaging initiated by 12 minutes, and $75 \%$ of patients had imaging initiated within 30 minutes.

Metric 3: $75 \%$ of patients being evaluated for revascularization should have imaging initiated within 30 minutes from time of arrival. At the best of centers with high volumes and an established resource infrastructure, this is expected to be achieved in 12 minutes.

Imaging to Puncture. The largest amount of time from door to revascularization comes from the steps from door to puncture rather than puncture to revascularization, and most endovascular treatment decisions are made after imaging. Therefore, the largest opportunities to reduce delays and improve outcomes will come from reducing imaging-to-puncture times. The recommended time from start of imaging to arterial puncture is 50 minutes or less. This is in keeping with the time intervals reported in the recent endovascular trials, which had a fastest 25 th percentile of 51 minutes, ${ }^{46}$ and it is the consensus of the writing group that this time metric is necessary, achievable, and consistent with the improvement in door-to-balloon times that have been achieved for acute myocardial infarction. The recent trials also reported that $75 \%$ of patients had an imaging-to-puncture time of no more than 110 minutes. For patients transferred from another site whose imaging does not need to be repeated, it is expected that door-to-puncture times can be reduced by 30 minutes.

Metric 4: $75 \%$ of patients treated with endovascular therapy should have an imaging-to-puncture time of 110 minutes or less. At the best of centers with high volumes and an established resource infrastructure, this is expected to be achieved in 50 minutes or less.

Metric 5: For patients transferred from another site in whom imaging is not repeated, $75 \%$ of patients being treated should have a door-to-puncture time of 80 minutes or less.

Imaging-to-Thrombus Time. Previous versions of this document have included imaging-to-thrombus time as a metric. This is no longer believed to be a necessary time point for measurement as a result of inaccuracies of measurement and inconsistent practice in documenting the same.

Puncture Time to Reperfusion. This metric assesses the efficiency of the interventional physician and team. Given the rapid advancements in endovascular treatment modalities, these recommendations are likely to change. In the Mechanical Embolus Removal in Cerebral Ischemia registry, ${ }^{41}$ the largest prospective endovascular data base to date reflecting procedural outcomes across a large variety of stroke centers in the United States, the median time from groin puncture to the end of the procedure was 90 minutes. Newer technologies such as "stentrievers" have been noted to achieve significantly shorter procedural times (median of approximately 50 minutes). ${ }^{46}$

Although time to final angiography is easily measured, it may be variable depending on the need to perform thrombolysis of peripheral-branch occlusions after recanalization of the proximal occlusion, as more complete revascularization is likely to lead to 
improved clinical outcomes, albeit at some increased procedural risk. The time metric described here for successful reperfusion represents the time to first reach an $m$ TICI grade $\geq 2 b$. Additional time, if required to achieve complete revascularization, ie, mTICI grade 3 , is not reflected in this metric. Recent trials have published their time intervals, and, by doing so, set new expectations. Median time from groin puncture to reperfusion in the SWIFT PRIME trial ${ }^{20}$ was 24 minutes (interquartile range, 18-33 minutes). The median puncture-to-reperfusion time in the HERMES collaboration $^{46}$ was 44 minutes (interquartile range, 27-64.5 minutes). Generally, we recommend that procedure times not exceed 60 minutes as in the recent trials, and the reperfusion target should be to reach $\mathrm{mTICI}$ grade $\geq 2 \mathrm{~b}$. ${ }^{20}$ This threshold is further clarified in the following section on recanalization/reperfusion.

Metric 6: In $70 \%$ of patients, mTICI grade $\geq 2 \mathrm{~b}$ should be reached ideally within 60 minutes of arterial puncture.

\section{Recanalization/Reperfusion}

Revascularization is key to improving outcomes with endovascular stroke therapy. Recanalization of the occluded vessel and reperfusion of the distal capillary bed are measures of revascularization, and, although intimately linked, are not necessarily interchangeable. Of the two measures, reperfusion of the distal capillary bed is most linked with clinical outcome. ${ }^{106}$ Reperfusion can be assessed by using CT or MR perfusion imaging. On angiography, crude assessment of reperfusion can be made by assessing blood flow into the distal bed, but this does not necessarily correlate with reperfusion on a microcirculatory level. ${ }^{106} \mathrm{Al}-$ though advances have been made in perfusion assessment in the angiographic suite, ${ }^{107}$ this assessment is not readily available at the present time. Therefore, most interventionalists will rely on a combination of recanalization and reperfusion to assess revascularization.

Revascularization can be assessed in a number of ways, including the thrombolysis in cerebral infarction (TICI) scale, ${ }^{108}$ the thrombolysis in myocardial infarction (TIMI) scale, ${ }^{109,110}$ the Mori reperfusion scale, ${ }^{111}$ the Qureshi scale, ${ }^{112}$ and the Arterial Occlusive Lesion score, ${ }^{113}$ among others. No direct comparisons of the revascularization scales in terms of their predictive ability for final infarct volume exist, but, through expert comparison of scales, the stroke and interventional community favors the use of the TICI scale. ${ }^{114,115}$ In a comparison of TIMI versus TICI scales, TICI was found to be superior to TIMI. The mTICI scale (Table 1) shifted the definition of a grade of $2 \mathrm{~b}$ to reperfusion of $>50 \%$ rather than $>66 \%$ of the distal territory, ${ }^{31}$ and mTICI grade $2 b / 3$ was used as the definition of procedural success in most successful endovascular trials. This is the scale recommended for future studies. ${ }^{30}$ A further refinement to the TICI scale introduced a new category of $2 c$ to define angiographic revascularization of $>90 \%$ and $<100 \%$ of the distal territory. ${ }^{116}$ However, the clinical applicability of TICI grade $2 \mathrm{c}$ has not been validated in larger prospective trials. Nevertheless, the higher the recanalization and reperfusion grade, the better the outcome, with particularly improved outcomes seen with grades of $2 \mathrm{~b}$ or higher ${ }^{116}$ and the best outcomes seen with TICI grade 3 revascularization. ${ }^{117}$

Compared with earlier studies, ${ }^{9,17}$ the positive clinical trials of endovascular stroke therapy showed vastly improved revascular- ization rates, with $\mathrm{mTICI}$ grade $2 \mathrm{~b} / 3$ rates ranging from $58.7 \%$ to $88.0 \%,{ }^{7,11,13,15,20}$ and the HERMES meta-analysis ${ }^{14}$ found an mTICI grade $2 \mathrm{~b} / 3$ rate of $71 \%$. The THERAPY trial ${ }^{18}$ reported an mTICI grade $2 b / 3$ rate of $73 \%$. This was assessed with the use of core laboratory adjudication in most studies, and it has been shown that local sites tend to overestimate the degree of reperfusion compared with a core laboratory. ${ }^{99}$ Postmarket registries have found mTICI grade $\geq 2 \mathrm{~b}$ rates of $70.9 \%-73.9 \%$, but no central adjudication was performed. ${ }^{97,118,119}$ Based on this, an mTICI grade $\geq 2 b$ rate of $70 \%$ seems a reasonable number for all acute ischemic strokes treated. Only moderate agreement exists between raters for the TICI scale, even though agreement is substantial when the scale is dichotomized into successful (ie, TICI grade $2 \mathrm{~b} / 3$ ) or unsuccessful outcomes (ie, TICI grade 0 , 1 , or 2a). ${ }^{120}$

In terms of technical success of procedures, it is also important to note the presence of distal embolization and embolization to new territory. ${ }^{31}$ The ultimate goal of revascularization is to improve patient outcomes. However, there is a risk that persistent attempts to recanalize an occlusion may lead to more complications. The combined metrics for SICH, revascularization, and mRS scores of $0-2$ measure these risks and benefits.

Metric 7: The mTICI scale should be the primary scale used to assess angiographic reperfusion.

Metric 8: At least $70 \%$ of patients should have mTICI grade $2 \mathrm{~b} / 3$ (ie, $>50 \%$ ) reperfusion for all clot locations.

\section{Postprocedural CT/MR Imaging}

Postprocedural imaging is necessary to identify acute SAH or parenchymal hematoma, differentiate intraparenchymal hemorrhage from contrast staining, define the overall extent of new stroke, and identify other findings. Although there is no evidence that this improves clinical outcomes, there is consensus based on European guidelines that postprocedural imaging is required. ${ }^{121}$ CT or MR imaging within 36 hours after intervention should be performed in all stroke patients. ${ }^{7,11,15,20}$ Although some patients may receive CT or MR imaging immediately after the procedure, imaging performed the next day provides additional valuable information. It is recognized that there are certain circumstances that might render follow-up imaging difficult or impossible to perform. Therefore, the threshold for this imaging is $90 \%$, acknowledging that a goal of $100 \%$ is desired.

Metric 9: At least 90\% of patients should have a brain CT or MR imaging examination within 36 hours of the end of the procedure.

\section{SICH}

The most common major risk of endovascular treatment of acute ischemic stroke is SICH. As defined by individual studies, the incidences of $\mathrm{SICH}$ following endovascular revascularization range from $2 \%$ to $10 \%$ for combined intravenous and intra-arterial thrombolytic trials ${ }^{9,12,39,122}$ and from $1 \%$ to $8 \%$ for EVT trials. ${ }^{7,11,13,20,121}$ Several definitions have been used, as described in the National Institute of Neurological Disorders and Stroke trial, ${ }^{1}$ the SITS-MOST ${ }^{33}$ and INSTOR registries, ${ }^{78}$ and European regis- 
tries such as SITS-Thrombectomy, ${ }^{32,81}$ MR CLEAN $^{82}$ (Netherlands), and the Heidelberg Bleeding Classification. ${ }^{34}$

$\mathrm{SAH}$ is a unique complication of endovascular therapy and is not typically seen with intravenous therapy with TPA alone. Intraprocedural SAH caused by arterial perforation can be rapidly fatal, but has been described as being asymptomatic in as many as $16 \%$ of patients treated with mechanical thrombectomy without perforation. $^{123}$

The definition chosen for SICH in this document is based on that used by the SWIFT PRIME trial ${ }^{20}$ and includes any intracranial hemorrhage with neurologic deterioration leading to an increase in NIHSS score $>4$ or leading to death within 24 hours of treatment.

SICH is not only an "end-result" evaluation of clinical judgment in the realm of patient selection and technical skill, but also a reflection of timing, procedural execution, and expeditious completion of the task. For these reasons, tracking of SICH is mandatory.

Metric 10: 100\% of cases with SICH are reviewed (see "Quality Improvement").

Metric 11: No more than 10\% of treated patients should develop SICH.

\section{Embolization of New Territory}

Embolization of previously unaffected territories and embolization as a result of clot fragmentation within the treated territory can occur during endovascular treatment. Distal embolization within the treated territory is different from embolization of new territory and has been reported in $16 \%$ of patients treated with endovascular thrombolysis and 35\% of patients treated with thrombectomy, without decreasing the likelihood of a favorable outcome. ${ }^{124,125}$ Embolization of new territory has been reported in 5\%-9\% of patients treated in the recent EVT trials ${ }^{7,13,20}$ and may cause new areas of symptomatic infarct or require additional treatment of previously unaffected vessels.

Metric 12: No more than $10 \%$ of patients should have embolization of new territory.

\section{Death within 72 Hours of Treatment}

Death within 72 hours of stroke is typically not a result of the stroke itself. The authors clearly acknowledge that every case is unique and that each instance needs to be reviewed in its entirety with the understanding that there are circumstances (eg, myocardial infarction) that lead to death in the short term and are unrelated to operator factors. Death soon after a procedure in and of itself does not imply or indicate a quality problem. However, all deaths within 72 hours are a trigger for review.

Metric 13: 100\% of cases of death within 72 hours of the end of the procedure are reviewed.

\section{Clinical Outcomes}

Ultimately, the goal of endovascular stroke therapy is to limit the size and extent (ie, severity) of stroke, improve the clinical outcome of the patient, and prevent long-term disability. By convention, these outcomes are commonly assessed by using various functional grading systems: during initial hospitalization, stroke is commonly assessed based on changes in the NIHSS score, and then, often at 90 days, by using the mRS. Clinical outcomes of stroke revascularization are multifactorial, depending on factors intrinsic to the patient such as pre-existing cerebral artery collateral vessels, procedural factors such as time to revascularization and completeness of revascularization, as well as the patient's response to a host of interventions in intensive care and then rehabilitation. Among specific patient factors, higher admission NIHSS scores and age were shown in the HERMES meta-analy$\operatorname{sis}^{14}$ to portend worse outcomes with medical or endovascular therapy. Other medical comorbidities such as underlying cardiac disease, hypertension, and diabetes mellitus all play a role in outcomes. From a procedural standpoint, higher rates of recanalization are associated with improved outcomes. A key component of any interventional stroke program is tracking of clinical outcomes. To that end, we propose that a discharge NIHSS score be documented on all patients, and that all patients are contacted and evaluated to obtain an mRS score at 90 days. Early improvement in NIHSS score may function as a surrogate marker of outcome in situations in which an mRS score cannot be obtained. ${ }^{126,127}$ Although it is ideal to assess the patient in person, this may not always be possible, and telephone assessment of mRS score is a reasonable alternative that is well validated. ${ }^{128}$ We understand that some patients may be lost to follow-up by 90 days.

Metric 14: All treated patients have a documented NIHSS score 20-36 hours after treatment and at discharge. Attempts are made to contact and document a follow-up mRS score at 90 days (evaluated in person or via telephone) on all treated patients. At least $90 \%$ of treated patients have documented 90 day mRS score.

Determining a single threshold level of "good clinical outcome" for all patient populations is difficult because of the heterogeneity of treated patients and the absence of comprehensive data. Individual centers, for example, may have a more elderly patient population or patients with later presentations. The incidences of patients with an mRS score of $0-2$ at 90 days in the recent randomized controlled endovascular trials ranged from $33 \%\left(\right.$ MR CLEAN) ${ }^{7}$ to $71 \%$ (EXTEND-IA), ${ }^{11}$ with an overall aggregate rate of $46 \%$ in the HERMES trial. ${ }^{14}$ Similarly, the THERAPY ${ }^{18}$ and Trial and Cost Effectiveness Evaluation of Intraarterial Thrombectomy in Acute Ischemic Stroke (THRACE) ${ }^{8}$ trials reported $38 \%$ and $53 \%$ rates of mRS score $0-2$ at 90 days, respectively, and, in the per-protocol population of the Pragmatic Ischemic Thrombectomy Evaluation (PISTE) trial, ${ }^{129} 57 \%$ of the endovascular group reached an mRS score of $0-2$ at 90 days.

The major trials focused on stroke patients with large artery occlusions, specifically internal carotid terminus or proximal middle cerebral (ie, M1) arteries. However, some patients with severe stroke have occlusions at other locations. Patients with isolated M2 branch occlusions may be reasonable candidates for EVT, but, in general, the natural history of stroke in these patients is better than those with more proximal occlusions. ${ }^{130}$ Although there are no randomized data showing a benefit for thrombectomy in basilar artery occlusions, these are often treated at many centers. ${ }^{131}$ Several studies have specifically reported worse outcomes for patients who did not meet the trial inclusion criteria or 
the current American Heart Association level IA recommendations. ${ }^{22}$ Gratz et al $^{119}$ reported $30 \%$ versus $57 \%$ incidences of mRS score of 0-2 for high-risk patients versus standard-risk patients. Similarly, Goyal et $\mathrm{al}^{75}$ reported $39 \%$ versus $47 \%$ incidences of mRS score of $0-2$ for patients not meeting versus meeting AHA level I recommendations.

One must take prestroke functional status into account when setting a threshold for 90-day mRS score for good outcome. Most patients in the recent randomized trials had an mRS score of $0 / 1$ at baseline. As described in the "Indications" section, this is not to imply that EVT be withheld for those who do not have an mRS score of $0 / 1$, but that any outcome threshold needs to account for prestroke functional status.

Multicenter registries have reported results with modern thrombectomy in more heterogeneous groups of patients, including patients with vertebrobasilar and M2 clot locations as well as tandem lesions. The registries include the German Register on Revascularization in Ischemic Stroke Patients (REVASK) registry ( $n=1,107$ patients, $40 \%$ mRS score $0-2$ at 90 days), ${ }^{132}$ the Catalonia stroke registry ( $n=536$ patients, $43 \% \mathrm{mRS}$ score $0-2$ at 90 days $),{ }^{118}$ the North American Solitaire registry $(n=354$ patients, $42 \% \mathrm{mRS}$ score $0-2$ at 90 days), ${ }^{133}$ and the Madrid registry ( $n=479,54 \%$ mRS score $0-2$ at 90 days). ${ }^{131}$ The Dutch MR CLEAN registry ${ }^{134}$ reported a $41 \%$ incidence of $m R S$ score $0-2$ at 90 days in a group of 1,321 patients. Compared with the randomized trials, the registries will include some patients at higher risk (ie, basilar occlusions), some at lower risk (ie, M2 occlusions), and some biased data, as the data are not adjudicated, likely leading to better reported outcomes. However, this is likely to be similar to the experiences of hospitals using the metrics of this document.

Clinical acumen is needed to determine the risk versus benefit of treatment based on published trial and registry data and personal experience. The AHA has created level I recommendations $^{22}$ for patient selection based on current randomized trials. However, we expect these recommendations to evolve as results from trials address "wake-up" strokes, prolonged time from symptom onset, basilar artery occlusions, large infarct size, and “mothership" versus “drip-and-ship" cases. ${ }^{48,49,54,55,59,135}$

We propose a single threshold for clinical outcomes for all treated patients regardless of whether they would have been candidates for most recent trials or meet the AHA level I recommendations. This is consistent with the heterogeneity of current clinical practice in which nearly half of treated patients do not meet the AHA recommendations. ${ }^{75}$ This document does not advocate for or against treating patients outside of the randomized trial or AHA level I recommendations, but suggests a threshold that recognizes the common practice of treating such patients. The threshold of a $30 \%$ incidence of mRS score of $0-2$ at 90 days is lower than those of the recent randomized trials and registries based on the experience that "off-trial" patients are more likely to be at higher risk for poor outcomes ${ }^{75,119}$ and the belief that the published registry results may not reflect the most current trends in patient selection. It is important to note that, although achieving an mRS score of $0-2$ is an important goal, it is not the only marker of a favorable outcome after endovascular therapy. Some patients may have important clinical benefit with an mRS score shift from 4/5 down to 3 . However, mRS score shift analysis re- quires a control group comparison, which is not useful as a quality metric. This suggested threshold should not dissuade centers from treating individual patients if they believe there is a potential benefit from the procedure. Given the multiple factors that influence outcomes, centers are encouraged to benchmark their outcomes against those from a similar patient population.

The clinical outcome threshold of this document is intended to prompt internal review of the endovascular stroke program. It is not designed to constitute a standard for reimbursement from payers, or for accreditation purposes. Local patient factors such as overall medical comorbidities and time from symptom onset to treatment should be taken into account when reviewing any single institution's performance. This is especially true in those patients who have a greater degree of prestroke disability or other comorbidities that may have excluded them from the recent randomized trials, but for whom treatment may be warranted.

Metric 15: Of all treated patients, at least $30 \%$ are independent (ie, mRS score $0-2$ ) at 90 days after treatment.

\section{QUALITY IMPROVEMENT \\ Ongoing Quality Improvement}

As EVT of acute ischemic stroke becomes a mainstream offering at many centers, an endovascular-specific multidisciplinary QI process should be established in all programs offering this treatment. ${ }^{24,25}$ These endovascular cases, similar to trauma cases, require complex processes of care. These processes go beyond the clinical and technical skills of the operators themselves and should be monitored in a continuous and ongoing fashion.

A peer-review committee at the local hospital should be formed that involves personnel from the several backgrounds that have expertise in stroke care as well as a vested interest in quality of care and outcomes. This committee should provide an open and transparent forum for process and case review. Transparency will optimize confidence in the process, which should have a positive impact on patient care. Although there may be potential for conflict or disagreement among various participants, it is vital that the process be viewed as a nonpolitical, nonpunitive instrument for care process improvement.

Specifically within the United States, in keeping with standards established under the Health Care Quality Improvement Act of 1986 (42 USC $\$ 11101$ et seq.), peer-review meetings and minutes are generally protected from legal inquiry in most states as long as the review is conducted under the auspices of the facility QI program. The Health Care Quality Improvement Act established standards for professional review actions. Although this protection is not absolute, if a professional review body meets these standards, neither the professional review body nor any person acting as a member or staff to the body will be liable for damages under most federal or state laws with respect to the action. ${ }^{136-139}$ All associated QI documents should include routine annotation that establishes the purpose of the document and that its content is protected under applicable federal or state law. The program should operate under the local facility umbrella established for all facility QI and peer-review initiatives. 
Table 3: Endovascular therapy quality improvement case review triggers and process metrics

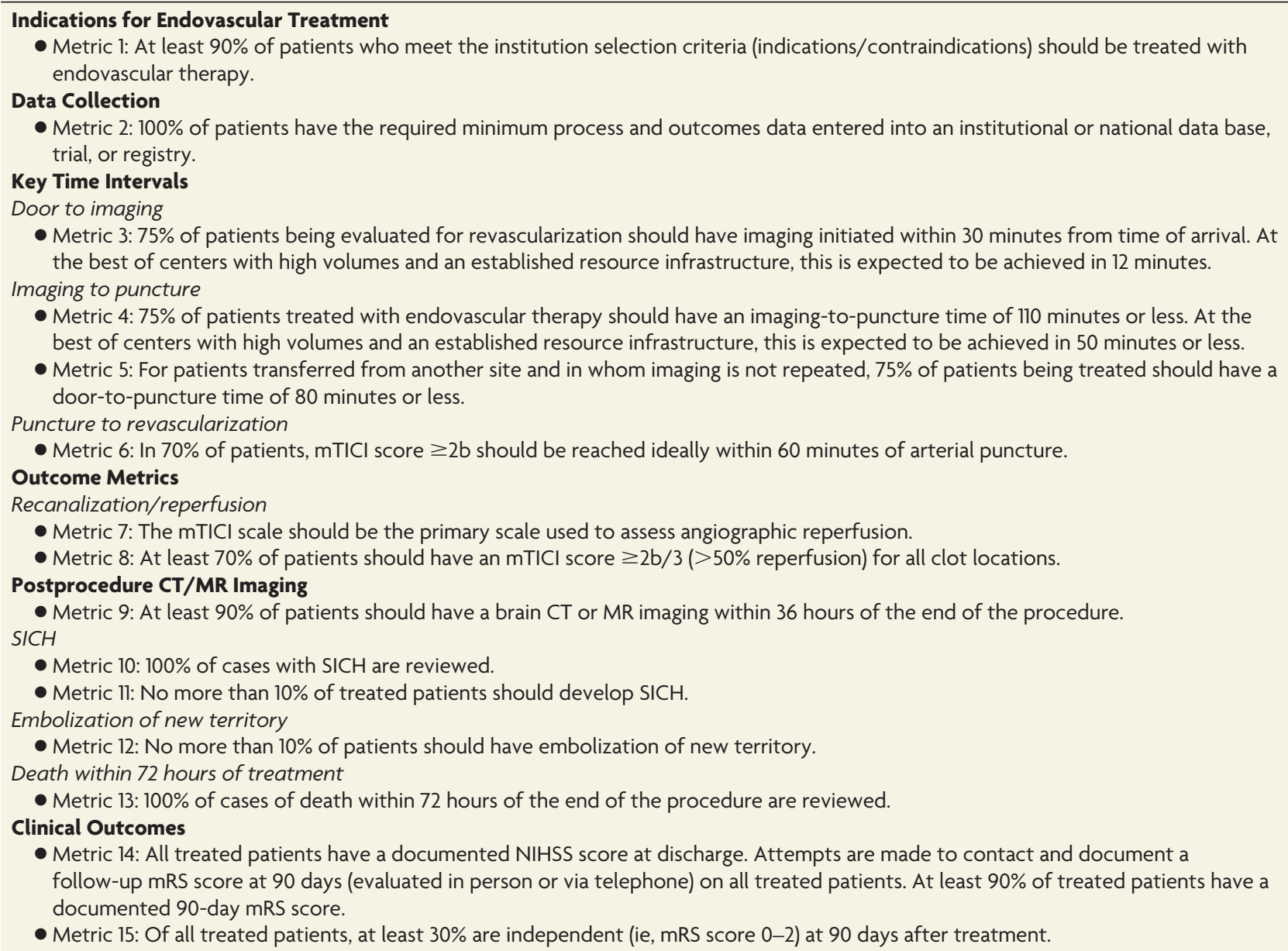

Note:-mRS indicates modified Rankin Scale; mTICI, modified thrombolysis in cerebral infarction; NIHSS, National Institutes of Health Stroke Scale; SICH, symptomatic intracranial hemorrhage.

\section{Peer Review Team}

It is recommended that, under the oversight of the stroke team medical director, a predetermined multidisciplinary subgroup consisting of medical personnel with familiarity and expertise in endovascular therapy be established to address issues specifically relating to endovascular treatment. Although a stroke neurologist is generally in the best overall position to objectively assess overall process deficiencies and outcomes, for technical and procedural issues, an interventionalist perspective must be considered. Ideally, the endovascular oversight team should be directed by a highly qualified and unbiased physician such as a noninterventional vascular neurologist. Depending on the institution, the endovascular QI peer group could include a variable combination of interventionalists, vascular neurologists, cerebrovascular neurosurgeons, intensivists, and diagnostic neuroradiologists. Additional members might include hospital representative(s) from the quality assurance/improvement or risk management departments, as well as possibly the stroke coordinator or other data personnel and secretarial support staff.

\section{Review Process}

The endovascular QI meeting should occur at least quarterly, and, depending on volume, may need to occur more frequently to provide adequate assessment and review. There should be review of every case in centers with volumes $<50$ cases per year and review of every case in which the parameters are outside the benchmarks (eg, prolonged time to puncture, failure of reperfusion, prolonged time to reperfusion) or in which a complication occurs (eg, SICH, embolization of new territory, or death within 72 hours). As noted earlier in the section on data collection, all cases should be entered into a trial, data base, or registry with national participation. ${ }^{24,25,76}$ In the United States, Medicare is functioning under the Medicare Access and Children's Health Insurance Program Reauthorization Act of 2015, ${ }^{140}$ which seeks to align disparate quality programs through Qualified Clinical Data Registries. This approach is in keeping with our aforementioned recommendation for data collection and quality control. ${ }^{141,142}$

The interventionalist who performed the specific case under review should be present to offer his/her observations and perspective. The focused endovascular peer review should routinely include assessment of technical factors such as device choice, supplemental lytic agent infusion, and equipment inventory assessment. Process elements such as on-call notification, timing (ie, door-to-imaging and imaging-to-arterial puncture times), procedure table setup, and overall communication should also receive routine attention. Performance review is not limited to the treating endovascular physician, but should also include the emergency department, neurology and neurointensive care personnel, 
interventional technologists, nursing staff, and other related service areas as indicated. Information concerning transfer from and communication with referring primary stroke centers before and after return to the primary center, complications, and 90-day functional outcome should also be routinely discussed and benchmarked.

\section{Triggers for Review}

Any event that might affect quality should be reviewed. Specific triggers for endovascular review include unmet process benchmarks, death, and symptomatic postprocedural hemorrhage. Some complications or process delays may be unavoidable, whereas others may reflect significant errors in judgment or process deficiencies. A determination must be made if the patient was harmed. Process problems such as delays or inadequate communication increase the risk of harm. Therefore, complications and events that increase the risk of poor outcomes need to be reviewed as a means of improving quality. There must also be differentiation between clearly procedure-related complications (eg, perforation and/or dissection, distal dislodgment of thrombus that remains unreachable, embolization of new territory, and immediate $\mathrm{SICH}$ following the procedure) and those that might be related to the primary ischemic event itself (eg, infarction, cerebral edema, and hemorrhagic transformation). Predisposing underlying vascular disease and comorbidities must also be considered.

Physicians who choose to treat sicker patients may have poorer outcomes and may not meet established benchmarks. These cases should not be considered in isolation, as a poor outcome does not necessarily indicate that such physicians are providing a lower quality of care, but rather that they have a different patient mix than the trials that were used to create the benchmarks. ${ }^{7,8,10,11,13-15,18,20,143-145}$ Adjusting for risk and severity may be helpful in assessing local outcomes compared with other institutions and benchmarks. Endovascular QI case review triggers and key process metrics are summarized in Table 3.

In addition to these morbidity and mortality markers, it is incumbent on the institution and the quality-assurance/improvement and peer-review committee to also assess the "good outcomes." A certain percentage of good outcomes are necessary for there to be sufficient benefit to the overall patient population. This document also defines minimal recanalization rates as well as improved clinical outcomes that should be attained.

\section{Performance and Process Improvement}

The committee should be equipped to deal with poor performance in a supportive, constructive, and collegial manner. In cases in which negative trends and deficiencies become apparent, improvement may require individual mentoring, additional education, or supplemental training. Endovascular stroke QI review of problematic cases should generate a specific course of action to remedy recognized problems and prevent future occurrences. Individual assignments should be tracked, with accountability reports scheduled for subsequent meetings. Further, process improvement is a continuing activity that, along with individual performance improvement, will significantly impact clinical outcomes. ${ }^{146}$

\section{ACKNOWLEDGMENTS}

The authors thank Zachary Zhang, MD (Rochester General Hospital, Rochester, New York), for assistance creating the evidence table and formatting the document; and Sean A. Kennedy, MD (University of Toronto, Toronto, Ontario), and Ajinkya Desai, MD (Rochester General Hospital, Rochester, New York), for assistance creating the evidence table.

\section{REFERENCES}

1. National Institute of Neurological Disorders and Stroke rt-PA Stroke Study Group. Tissue plasminogen activator for acute ischemic stroke. N Engl J Med 1995;333:1581-87 CrossRef Medline

2. Mozaffarian D, Benjamin EJ, Go AS, et al; American Heart Association Statistics Committee and Stroke Statistics Subcommittee. Heart disease and stroke statistics-2015 update: a report from the American Heart Association. Circulation 2015;131:e29-322 CrossRef Medline

3. Gibson CM, Pride YB, Frederick PD, et al. Trends in reperfusion strategies, door-to-needle and door-to-balloon times, and in-hospital mortality among patients with ST-segment elevation myocardial infarction enrolled in the National Registry of Myocardial Infarction from 1990 to 2006. Am Heart J 2008;156:1035-44 CrossRef Medline

4. Sacks D, Black CM, Cognard C, et al; American Society of Neuroradiology, Canadian Interventional Radiology Association, Cardiovascular and Interventional Radiological Society of Europe, Society for Cardiovascular Angiography and Interventions, Society of Interventional Radiology, Society of NeuroInterventional Surgery, European Society of Minimally Invasive Neurological Therapy, Society of Vascular and Interventional Neurology. Multisociety consensus quality improvement guidelines for intraarterial catheter-directed treatment of acute ischemic stroke, from the American Society of Neuroradiology, Canadian Interventional Radiology Association, Cardiovascular and Interventional Radiological Society of Europe, Society for Cardiovascular Angiography and Interventions, Society of Interventional Radiology, Society of NeuroInterventional Surgery, European Society of Minimally Invasive Neurological Therapy, and Society of Vascular and Interventional Neurology. J Vasc Interv Radiol 2013;24:151-63 CrossRef Medline

5. White PM, Bhalla A, Dinsmore J, et al. Standards for providing safe acute ischaemic stroke thrombectomy services (September 2015). Clin Radiol 2017;72:175.e1-9 CrossRef Medline

6. Badhiwala JH, Nassiri F, Alhazzani W, et al. Endovascular thrombectomy for acute ischemic stroke: a meta-analysis. JAMA 2015; 314:1832-43 CrossRef Medline

7. Berkhemer OA, Fransen PS, Beumer D, et al. A randomized trial of intraarterial treatment for acute ischemic stroke. $N$ Engl J Med 2015;372:11-20 CrossRef Medline

8. Bracard S, Ducrocq X, Mas JL, et al; THRACE investigators. Mechanical thrombectomy after intravenous alteplase versus alteplase alone after stroke (THRACE): a randomised controlled trial. Lancet Neurol 2016;15:1138-47 CrossRef Medline

9. Broderick JP, Palesch YY, Demchuk AM, et al; Interventional Management of Stroke (IMS) III Investigators. Endovascular therapy after intravenous t-PA versus t-PA alone for stroke. $N$ Engl $\mathrm{J} \mathrm{Med}$ 2013;368:893-903 CrossRef Medline

10. Campbell BC, Hill MD, Rubiera M, et al. Safety and efficacy of Solitaire stent thrombectomy: individual patient data metaanalysis of randomized trials. Stroke 2016;47:798-806 CrossRef Medline

11. Campbell BC, Mitchell PJ, Kleinig TJ, et al; EXTEND-IA Investigators. Endovascular therapy for ischemic stroke with perfusion-imaging selection. N Engl J Med 2015;372:1009-18 CrossRef Medline

12. Ciccone A, Valvassori L, Nichelatti M, et al; SYNTHESIS Expansion Investigators. Endovascular treatment for acute ischemic stroke. N Engl J Med 2013;368:904-13 CrossRef Medline 
13. Goyal M, Demchuk AM, Menon BK, et a; ESCAPE Trial Investigators. Randomized assessment of rapid endovascular treatment of ischemic stroke. N Engl J Med 2015;372:1019-30 CrossRef Medline

14. Goyal M, Menon BK, van Zwam WH, et al; HERMES collaborators. Endovascular thrombectomy after large-vessel ischaemic stroke: a meta-analysis of individual patient data from five randomised trials. Lancet 2016;387:1723-31 CrossRef Medline

15. Jovin TG, Chamorro A, Cobo E, et al; REVASCAT Trial Investigators. Thrombectomy within $\mathbf{8}$ hours after symptom onset in ischemic stroke. N Engl J Med 2015;372:2296-306 CrossRef Medline

16. Kennedy SA, Baerlocher MO, Baerlocher F, et al. Meta-analysis of local endovascular therapy for acute ischemic stroke. J Vasc Interv Radiol 2016;27:307-21.e2 CrossRef Medline

17. Kidwell CS, Jahan R, Gornbein J, et al; MR RESCUE Investigators. A trial of imaging selection and endovascular treatment for ischemic stroke. N Engl J Med 2013;368:914-23 CrossRef Medline

18. Mocco J, Zaidat OO, von Kummer R, et al; THERAPY Trial Investigators. Aspiration thrombectomy after intravenous alteplase versus intravenous alteplase alone. Stroke 2016;47:2331-38 CrossRef Medline

19. Prabhakaran S, Ruff I, Bernstein RA. Acute stroke intervention: a systematic review. JAMA 2015;313:1451-62 CrossRef Medline

20. Saver JL, Goyal M, Bonafe A, et al; SWIFT PRIME Investigators. Stent-retriever thrombectomy after intravenous t-PA vs. t-PA alone in stroke. N Engl J Med 2015;372:2285-95 CrossRef Medline

21. NICE Interventional Procedure Guidance. Mechanical clot retrieval for treating acute ischaemic stroke. Interventional procedures guidance (IPG548), February 2016. http://www.nice.org.uk/guidance/ ipg548. Accessed April 10, 2016

22. Powers WJ, Derdeyn CP, Biller J, et al; American Heart Association Stroke Council. 2015 American Heart Association/American Stroke Association Focused Update of the 2013 Guidelines for the Early Management of Patients with Acute Ischemic Stroke Regarding Endovascular Treatment: A Guideline for Healthcare Professionals from the American Heart Association/American Stroke Association. Stroke 2015;46:3020 -35 CrossRef Medline

23. Wahlgren N, Moreira T, Michel P, et al; ESO-KSU, ESO, ESMINT, ESNR and EAN. Mechanical thrombectomy in acute ischemic stroke: consensus statement by ESO-Karolinska Stroke Update 2014/2015, supported by ESO, ESMINT, ESNR and EAN. Int $J$ Stroke 2016;11:134-47 CrossRef Medline

24. Connors JJ 3rd, Sacks D, Black CM, et al; Society of Interventional Radiology. Training guidelines for intra-arterial catheter-directed treatment of acute ischemic stroke: a statement from a special writing group of the Society of Interventional Radiology. J Vasc Interv Radiol 2009;20:1507-22 CrossRef Medline

25. Lavine SD, Cockroft K, Hoh B, et al. Training Guidelines for Endovascular Ischemic Stroke Intervention: An International MultiSociety Consensus Document. AJNR Am J Neuroradiol 2016;37: E31-34 CrossRef Medline

26. Jovin TG, Albers GW, Liebeskind DS; STAIR IX Consortium. Stroke treatment academic industry roundtable: the next generation of endovascular trials. Stroke 2016;47:2656-65 CrossRef Medline

27. Fink A, Kosecoff J, Chassin M, et al. Consensus methods: characteristics and guidelines for use. Am J Public Health 1984;74:979-83 CrossRef Medline

28. Institute of Medicine (U.S.) Committee on Standards for Developing Trustworthy Clinical Practice Guidelines. Graham R, Mancher M, Wolman DM, et al, eds. Clinical Practice Guidelines We Can Trust. Washington, DC: National Academies Press; 2011: xxxiv

29. Sacco RL, Kasner SE, Broderick JP, et al; American Heart Association Stroke Council, Council on Cardiovascular Surgery and Anesthesia, Council on Cardiovascular Radiology and Intervention, Council on Cardiovascular and Stroke Nursing, Council on Epidemiology and Prevention, Council on Peripheral Vascular Disease, Council on Nutrition, Physical Activity and Metabolism. An updated definition of stroke for the 21st century: a statement for healthcare professionals from the American Heart Association/
American Stroke Association. Stroke 2013;44:2064-89 CrossRef Medline

30. Wintermark M, Albers GW, Broderick JP, et al. Acute stroke imaging research roadmap II. Stroke 2013;44:2628-39 CrossRef Medline

31. Zaidat OO, Yoo AJ, Khatri P, et al; Cerebral Angiographic Revascularization Grading (CARG) Collaborators, STIR Revascularization working group, STIR Thrombolysis in Cerebral Infarction (TICI) Task Force. Recommendations on angiographic revascularization grading standards for acute ischemic stroke: a consensus statement. Stroke 2013;44:2650-63 CrossRef Medline

32. Wahlgren N, Ahmed N, Eriksson N, et al; Safe Implementation of Thrombolysis in Stroke-MOnitoring STudy Investigators. Multivariable analysis of outcome predictors and adjustment of main outcome results to baseline data profile in randomized controlled trials: Safe Implementation of Thrombolysis in Stroke-Monitoring Study (SITS-MOST). Stroke 2008;39:3316-22 CrossRef Medline

33. Wahlgren N, Ahmed N, Davalos A, et al; SITS-MOST investigators. Thrombolysis with alteplase for acute ischaemic stroke in the Safe Implementation of Thrombolysis in Stroke-Monitoring study (SITS-MOST): an observational study. Lancet 2007;369:275-82 CrossRef Medline

34. von Kummer R, Broderick JP, Campbell BC, et al. The Heidelberg Bleeding Classification: classification of bleeding events after ischemic stroke and reperfusion therapy. Stroke 2015;46:2981-86 CrossRef Medline

35. van Swieten JC, Koudstaal PJ, Visser MC, et al. Interobserver agreement for the assessment of handicap in stroke patients. Stroke 1988;19:604-07 CrossRef Medline

36. Casaubon LK, Boulanger JM, Blacquiere D, et al; Heart and Stroke Foundation of Canada Canadian Stroke Best Practices Advisory Committee. Canadian Stroke Best Practice Recommendations: Hyperacute Stroke Care Guidelines, Update 2015. Int J Stroke 2015; 10:924-40 CrossRef Medline

37. Campbell BC, Donnan GA, Lees KR, et al. Endovascular stent thrombectomy: the new standard of care for large vessel ischaemic stroke. Lancet Neurol 2015;14:846-54 CrossRef Medline

38. Coutts SB, Modi J, Patel SK, et al; Calgary Stroke Program. CT/CT angiography and MRI findings predict recurrent stroke after transient ischemic attack and minor stroke: results of the prospective CATCH study. Stroke 2012;43:1013-17 CrossRef Medline

39. Furlan A, Higashida R, Wechsler L, et al. Intra-arterial prourokinase for acute ischemic stroke: the PROACT II study-a randomized controlled trial. Prolyse in Acute Cerebral Thromboembolism. JAMA 1999;282:2003-11 CrossRef Medline

40. Penumbra Pivotal Stroke Trial Investigators. Penumbra pivotal stroke trial: the penumbra pivotal stroke trial—safety and effectiveness of a new generation of mechanical devices for clot removal in intracranial large vessel occlusive disease. Stroke 2009;40: 2761-68 CrossRef Medline

41. Smith WS, Sung G, Saver J, et al; Multi MERCI Investigators. Mechanical thrombectomy for acute ischemic stroke: final results of the Multi MERCI trial. Stroke 2008;39:1205-12 CrossRef Medline

42. Tarr R, Hsu D, Kulcsar Z, et al. The POST trial: initial post-market experience of the Penumbra system: revascularization of large vessel occlusion in acute ischemic stroke in the United States and Europe. J Neurointerv Surg 2010;2:341-44 CrossRef Medline

43. Fransen PS, Berkhemer OA, Lingsma HF, et al. Time to Reperfusion and Treatment Effect for Acute Ischemic Stroke: a randomized clinical trial. JAMA Neurol 2016;73:190-96 CrossRef Medline

44. Goyal M, Jadhav AP, Bonafe A, et al; SWIFT PRIME investigators. Analysis of workflow and time to treatment and the effects on outcome in endovascular treatment of acute ischemic stroke: results from the SWIFT PRIME randomized controlled trial. Radiology 2016;279:888-97 CrossRef Medline

45. Khatri P, Abruzzo T, Yeatts SD, et al; IMS I and II Investigators. Good clinical outcome after ischemic stroke with successful revascularization is time-dependent. Neurology 2009;73:1066-72 CrossRef Medline 
46. Saver JL, Goyal M, van der Lugt A, et al; HERMES Collaborators. Time to treatment with endovascular thrombectomy and outcomes from ischemic stroke: a meta-analysis. JAMA 2016;316: 1279-88 CrossRef Medline

47. Lansberg MG, Cereda CW, Mlynash M, et al; Diffusion and Perfusion Imaging Evaluation for Understanding Stroke Evolution 2 (DEFUSE 2) Study Investigators. Response to endovascular reperfusion is not time-dependent in patients with salvageable tissue. Neurology 2015;85:708-14 CrossRef Medline

48. Nogueira R, Jovin T. Clinical mismatch in the triage of wake up and late presenting strokes undergoing neurointervention with Trevo (DAWN). N Engl J Med 2018;378:11-21

49. POSITIVE Stroke Clinical Trial. https://clinicaltrials.gov/ct2/show/ NCT01852201 term $=$ positive + stroke + trial\&rank $=1$. Accessed February 12,2016

50. Endovascular Therapy Following Imaging Evaluation for Ischemic Stroke 3 (DEFUSE 3). https://clinicaltrials.gov/ct2/show/NCT02586415. Accessed February 12, 2016

51. Brandt T, von Kummer R, Müller-Küppers M, et al. Thrombolytic therapy of acute basilar artery occlusion: variables affecting recanalization and outcome. Stroke 1996;27:875-81 CrossRef Medline

52. Lin DD, Gailloud P, Beauchamp NJ, et al. Combined stent placement and thrombolysis in acute vertebrobasilar ischemic stroke. AJNR Am J Neuroradiol 2003;24:1827-33 Medline

53. Schonewille WJ, Wijman CA, Michel P, et al; BASICS study group. Treatment and outcomes of acute basilar artery occlusion in the Basilar Artery International Cooperation Study (BASICS): a prospective registry study. Lancet Neurol 2009;8:724-30 CrossRef Medline

54. Basilar Artery International Cooperation Study (BASICS). https:// clinicaltrials.gov/ct2/show/NCT01717755?term = basics + stroke + trial\&rank=1. Accessed April 11, 2017

55. Basilar Artery Occlusion Chinese Endovascular Trial. https:// clinicaltrials.gov/ct2/show/NCT02737189?term = best + stroke+ trial\&rank=2. Accessed April 11, 2017

56. Hacke W, Kaste M, Fieschi C, et al. Randomised double-blind placebo-controlled trial of thrombolytic therapy with intravenous alteplase in acute ischaemic stroke (ECASS II): Second EuropeanAustralasian Acute Stroke Study Investigators. Lancet 1998;352: 1245-51 CrossRef Medline

57. Barber PA, Demchuk AM, Zhang J, et al. Validity and reliability of a quantitative computed tomography score in predicting outcome of hyperacute stroke before thrombolytic therapy: ASPECTS Study Group-Alberta Stroke Programme Early CT Score. Lancet 2000;355:1670-74 CrossRef Medline

58. Pexman JH, Barber PA, Hill MD, et al. Use of the Alberta Stroke Program early CT score (ASPECTS) for assessing CT scans in patients with acute stroke. AJNR Am J Neuroradiol 2001;22:1534-42 Medline

59. Efficacy and Safety of Thrombectomy in Stroke with Extended Lesion and Extended Time Window (Tension). https://clinicaltrials. gov/show/NCT03094715. Accessed April 11, 2017

60. Riedel CH, Zoubie J, Ulmer S, et al. Thin-slice reconstructions of nonenhanced CT images allow for detection of thrombus in acute stroke. Stroke 2012;43:2319-23 CrossRef Medline

61. Riedel CH, Zimmermann P, Jensen-Kondering U, et al. The importance of size: successful recanalization by intravenous thrombolysis in acute anterior stroke depends on thrombus length. Stroke 2011;42:1775-77 CrossRef Medline

62. Rohan V, Baxa J, Tupy R, et al. Length of occlusion predicts recanalization and outcome after intravenous thrombolysis in middle cerebral artery stroke. Stroke 2014;45:2010-17 CrossRef Medline

63. Ahn SH, d'Esterre CD, Qazi EM, et al. Occult anterograde flow is an under-recognized but crucial predictor of early recanalization with intravenous tissue-type plasminogen activator. Stroke 2015; 46:968-75 CrossRef Medline

64. Menon BK, d'Esterre CD, Qazi EM, et al. Multiphase CT angiography: a new tool for the imaging triage of patients with acute ischemic stroke. Radiology 2015;275:510-20 CrossRef Medline

65. Gilgen MD, Klimek D, Liesirova KT, et al. Younger stroke patients with large pretreatment diffusion-weighted imaging lesions may benefit from endovascular treatment. Stroke 2015;46:2510-16 CrossRef Medline

66. Borst J, Berkhemer OA, Roos YB, et al; MR CLEAN investigators. Value of computed tomographic perfusion-based patient selection for intra-arterial acute ischemic stroke treatment. Stroke 2015;46:3375-82 CrossRef Medline

67. d'Esterre CD, Boesen ME, Ahn SH, et al. Time-dependent computed tomographic perfusion thresholds for patients with acute ischemic stroke. Stroke 2015;46:3390-97 CrossRef Medline

68. Barreto $\mathrm{AD}$, Albright $\mathrm{KC}$, Hallevi $\mathrm{H}$, et al. Thrombus burden is associated with clinical outcome after intra-arterial therapy for acute ischemic stroke. Stroke 2008;39:3231-35 CrossRef Medline

69. Lin R, Vora N, Zaidi S, et al. Mechanical approaches combined with intra-arterial pharmacological therapy are associated with higher recanalization rates than either intervention alone in revascularization of acute carotid terminus occlusion. Stroke 2009;40:2092-97 CrossRef Medline

70. Shi ZS, Loh Y, Walker G, et al; MERCI and Multi-MERCI Investigators. Clinical outcomes in middle cerebral artery trunk occlusions versus secondary division occlusions after mechanical thrombectomy: pooled analysis of the Mechanical Embolus Removal in Cerebral Ischemia (MERCI) and multi MERCI trials. Stroke 2010;41:953-60 CrossRef Medline

71. Coutinho JM, Liebeskind DS, Slater LA, et al. Mechanical thrombectomy for isolated M2 occlusions: a post hoc analysis of the STAR, SWIFT, and SWIFT PRIME studies. AJNR Am JNeuroradiol 2016;37:667-72 CrossRef Medline

72. Busl KM, Nogueira RG, Yoo AJ, et al. Prestroke dementia is associated with poor outcomes after reperfusion therapy among elderly stroke patients. J Stroke Cerebrovasc Dis 2013;22:718-24 CrossRef Medline

73. Khatri P, Hill MD, Palesch YY, et al; Interventional Management of Stroke III Investigators. Methodology of the Interventional Management of Stroke III Trial. Int J Stroke 2008;3:130-37 CrossRef Medline

74. Bhole R, Goyal N, Nearing K, et al. Implications of limiting mechanical thrombectomy to patients with emergent large vessel occlusion meeting top tier evidence criteria. J Neurointerv Surg 2017; 9:225-28 CrossRef Medline

75. Goyal N, Tsivgoulis G, Frei D, et al. A multicenter study of the safety and effectiveness of mechanical thrombectomy for patients with acute ischemic stroke not meeting top-tier evidence criteria. J Neurointerv Surg 2018;10:10-16 CrossRef Medline

76. Leifer D, Bravata DM, Connors JJ 3rd, et al; American Heart Association Special Writing Group of the Stroke Council, Atherosclerotic Peripheral Vascular Disease Working Group, Council on Cardiovascular Surgery and Anesthesia, Council on Cardiovascular Nursing. Metrics for measuring quality of care in comprehensive stroke centers: detailed follow-up to Brain Attack Coalition comprehensive stroke center recommendations: a statement for healthcare professionals from the American Heart Association/American Stroke Association. Stroke 2011;42:849-77 CrossRef Medline

77. Saver JL, Gornbein J. Treatment effects for which shift or binary analyses are advantageous in acute stroke trials. Neurology 2009; 72:1310-15 CrossRef Medline

78. Interventional Stroke Therapy Outcomes Registry (INSTOR). http:// www.strokeregistry.org. Accessed July 19, 2016

79. Meyers PM, Schumacher HC, Alexander MJ, et al; Wrting Group for American Academy of Neurology, American Association of Neurological Surgeons Cerebrovascular Section, Society of Neurointerventional Surgery and Society of Vascular and Interventional Neurology. Performance and training standards for endovascular ischemic stroke treatment. J Stroke Cerebrovasc Dis 2009;18:411-15 CrossRef Medline 
80. Schwamm LH, Fonarow GC, Reeves MJ, et al. Get With the Guideline: Stroke is associated with sustained improvement in care for patients hospitalized with acute stroke or transient ischemic attack. Circulation 2009;119:107-15 CrossRef Medline

81. SITS-Thrombectomy registry. http://www.sitsinternational.org/ registries/sits-thrombectomy/. Accessed August 12, 2016

82. MR CLEAN-R Registry. http://www.mrclean-trial.org. Accessed August 12, 2016

83. Menon BK, Saver JL, Goyal M, et al. Trends in endovascular therapy and clinical outcomes within the nationwide Get With The Guidelines-Stroke registry. Stroke 2015;46:989-95 CrossRef Medline

84. Hacke W, Donnan G, Fieschi C, et al; ATLANTIS Trials Investigators, ECASS Trials Investigators, NINDS rt-PA Study Group Investigators. Association of outcome with early stroke treatment: pooled analysis of ATLANTIS, ECASS, and NINDS rt-PA stroke trials. Lancet 2004;363:768-74 CrossRef Medline

85. Lansberg MG, Schrooten M, Bluhmki E, et al. Treatment time-specific number needed to treat estimates for tissue plasminogen activator therapy in acute stroke based on shifts over the entire range of the modified Rankin Scale. Stroke 2009;40:2079-84 CrossRef Medline

86. Menon BK, Sajobi TT, Zhang Y, et al. Analysis of workflow and time to treatment on thrombectomy outcome in the Endovascular Treatment for Small Core and Proximal Occlusion Ischemic Stroke (ESCAPE) randomized, controlled trial. Circulation 2016; 133:2279-86 CrossRef Medline

87. Ribo M, Molina CA, Cobo E, et al; REVASCAT Trial Investigators. Association between time to reperfusion and outcome is primarily driven by the time from imaging to reperfusion. Stroke 2016;47: 999-1004 CrossRef Medline

88. Bradley EH, Curry LA, Webster TR, et al. Achieving rapid door-toballoon times: how top hospitals improve complex clinical systems. Circulation 2006;113:1079-85 CrossRef Medline

89. Krumholz HM, Bradley EH, Nallamothu BK, et al. A campaign to improve the timeliness of primary percutaneous coronary intervention: Door-to-Balloon-An Alliance for Quality. JACC Cardiovasc Interv 2008;1:97-104 CrossRef Medline

90. Fonarow GC, Smith EE, Saver JL, et al. Improving door-to-needle times in acute ischemic stroke: the design and rationale for the American Heart Association/American Stroke Association's target-stroke initiative. Stroke 2011;42:2983-89 CrossRef Medline

91. Mitka M. Reducing door-to-needle time for tPA use remains an elusive goal in stroke care. JAMA 2011;305:1288-89 CrossRef Medline

92. Meretoja A, Strbian D, Mustanoja S, et al. Reducing in-hospital delay to 20 minutes in stroke thrombolysis. Neurology 2012;79: 306-13 CrossRef Medline

93. Rai AT, Smith MS, Boo S, et al. The 'pit-crew' model for improving door-to-needle times in endovascular stroke therapy: a Six-Sigma project. J Neurointerv Surg 2016;8:447-52 CrossRef Medline

94. Costalat V, Machi P, Lobotesis K, et al. Rescue, combined, and stand-alone thrombectomy in the management of large vessel occlusion stroke using the Solitaire device: a prospective 50-patient single-center study: timing, safety, and efficacy. Stroke 2011;42: 1929-35 CrossRef Medline

95. Miley JT, Memon MZ, Hussein HM, et al. A multicenter analysis of "time to microcatheter" for endovascular therapy in acute ischemic stroke. J Neuroimaging 2011;21:159-64 CrossRef Medline

96. Sun CH, Ribo M, Goyal M, et al. Door-to-puncture: a practical metric for capturing and enhancing system processes associated with endovascular stroke care, preliminary results from the rapid reperfusion registry. J Am Heart Assoc 2014;3:e000859 CrossRef Medline

97. Zaidat OO, Castonguay AC, Gupta R, et al. North American Solitaire Stent Retriever Acute Stroke Registry: post-marketing revascularization and clinical outcome results. J Neurointerv Surg 2014; 6:584-88 CrossRef Medline

98. Nogueira RG, Lutsep HL, Gupta R, et al; TREVO 2 Trialists. Trevo versus Merci retrievers for thrombectomy revascularisation of large vessel occlusions in acute ischaemic stroke (TREVO 2): a randomised trial. Lancet 2012;380:1231-40 CrossRef Medline

99. Saver JL, Jahan R, Levy EI, et al. Solitaire flow restoration device versus the Merci Retriever in patients with acute ischaemic stroke (SWIFT): a randomised, parallel-group, non-inferiority trial. Lancet 2012;380:1241-49 CrossRef Medline

100. Abilleira S, Ribera A, Dávalos A, et al; Catalan Stroke Code and Reperfusion Consortium. Functional outcome after primary endovascular therapy or IV thrombolysis alone for stroke: an observational, comparative effectiveness study. Cerebrovasc Dis 2014;38: 328-36 CrossRef Medline

101. Goyal M, Almekhlafi MA, Fan L, et al. Evaluation of interval times from onset to reperfusion in patients undergoing endovascular therapy in the Interventional Management of Stroke III trial. Circulation 2014;130:265-72 CrossRef Medline

102. van Heerden J, Yan B, Churilov L, et al. Picture-to-puncture time in acute stroke endovascular intervention: are we getting faster? J Neurointerv Surg 2015;7:564-68 CrossRef Medline

103. Nikoubashman O, Probst T, Schürmann K, et al. Weekend effect in endovascular stroke treatment: do treatment decisions, procedural times, and outcome depend on time of admission? J Neurointerv Surg 2017;9:336-39 CrossRef Medline

104. Latchaw RE, Alberts MJ, Lev MH, et al; American Heart Association Council on Cardiovascular Radiology and Intervention, Stroke Council, and the Interdisciplinary Council on Peripheral Vascular Disease. Recommendations for imaging of acute ischemic stroke: a scientific statement from the American Heart Association. Stroke 2009;40:3646-78 CrossRef Medline

105. McTaggart RA, Ansari SA, Goyal M, et al; Standards and Guidelines Committee of the Society of NeuroInterventional Surgery (SNIS). Initial hospital management of patients with emergent large vessel occlusion (ELVO): report of the standards and guidelines committee of the Society of NeuroInterventional Surgery. J Neurointerv Surg 2017;9:316-23 CrossRef Medline

106. Cho TH, Nighoghossian N, Mikkelsen IK, et al. Reperfusion within 6 hours outperforms recanalization in predicting penumbra salvage, lesion growth, final infarct, and clinical outcome. Stroke 2015;46:1582-89 CrossRef Medline

107. Struffert T, Deuerling-Zheng Y, Engelhorn T, et al. Feasibility of cerebral blood volume mapping by flat panel detector CT in the angiography suite: first experience in patients with acute middle cerebral artery occlusions. AJNR Am J Neuroradiol 2012;33:618-25 CrossRef Medline

108. Higashida RT, Furlan AJ, Roberts H, et al; Technology Assessment Committee of the American Society of Interventional and Therapeutic Neuroradiology, Technology Assessment Committee of the Society of Interventional Radiology. Trial design and reporting standards for intra-arterial cerebral thrombolysis for acute ischemic stroke. Stroke 2003;34:e109-37 CrossRef Medline

109. TIMI Study Group. The Thrombolysis in Myocardial Infarction (TIMI) trial: Phase I findings. N Engl J Med 1985;312:932-36 Medline

110. Chesebro JH, Knatterud G, Roberts R, et al. Thrombolysis in Myocardial Infarction (TIMI) Trial, Phase I: a comparison between intravenous tissue plasminogen activator and intravenous streptokinase-clinical findings through hospital discharge. Circulation 1987;76:142-54 CrossRef Medline

111. Mori E, Yoneda Y, Tabuchi M, et al. Intravenous recombinant tissue plasminogen activator in acute carotid artery territory stroke. Neurology 1992;42:976-82 CrossRef Medline

112. Qureshi AI. New grading system for angiographic evaluation of arterial occlusions and recanalization response to intra-arterial thrombolysis in acute ischemic stroke. Neurosurgery 2002;50: 1405-14; discussion 1414-15 Medline

113. Khatri P, Neff J, Broderick JP, et al; IMS-I Investigators. Revascularization end points in stroke interventional trials: recanalization 
versus reperfusion in IMS-I. Stroke 2005;36:2400-03 CrossRef Medline

114. Gerber JC, Miaux YJ, von Kummer R. Scoring flow restoration in cerebral angiograms after endovascular revascularization in acute ischemic stroke patients. Neuroradiology 2015;57:227-40 CrossRef Medline

115. Zaidat OO, Lazzaro MA, Liebeskind DS, et al. Revascularization grading in endovascular acute ischemic stroke therapy. Neurology 2012;79(13 Suppl 1):S110-16 CrossRef Medline

116. Almekhlafi MA, Mishra S, Desai JA, et al. Not all "successful" angiographic reperfusion patients are an equal validation of a modified TICI scoring system. Interv Neuroradiol 2014;20:21-27 CrossRef Medline

117. Kleine JF, Wunderlich S, Zimmer C, et al. Time to redefine success? TICI 3 versus TICI $2 b$ recanalization in middle cerebral artery occlusion treated with thrombectomy. J Neurointerv Surg 2017;9: 117-21 CrossRef Medline

118. Abilleira S, Cardona P, Ribo M, et al; Catalan Stroke Code and Reperfusion Consortium. Outcomes of a contemporary cohort of 536 consecutive patients with acute ischemic stroke treated with endovascular therapy. Stroke 2014;45:1046-52 CrossRef Medline

119. Gratz PP, Jung S, Schroth G, et al. Outcome of standard and highrisk patients with acute anterior circulation stroke after stent retriever thrombectomy. Stroke 2014;45:152-58 CrossRef Medline

120. Gaha M, Roy C, Estrade L, et al. Inter- and intraobserver agreement in scoring angiographic results of intra-arterial stroke therapy. AJNR Am J Neuroradiol 2014;35:1163-69 CrossRef Medline

121. Fiehler J, Cognard C, Gallitelli M, et al. European Recommendations on Organisation Of Interventional Care in Acute Stroke (EROICAS). Int J Stroke 2016;11:701-16 CrossRef Medline

122. Ogawa A, Mori E, Minematsu K, et al; MELT Japan Study Group. Randomized trial of intraarterial infusion of urokinase within 6 hours of middle cerebral artery stroke: the middle cerebral artery embolism local fibrinolytic intervention trial (MELT) Japan. Stroke 2007;38:2633-39 CrossRef Medline

123. Yoon W, Jung MY, Jung SH, et al. Subarachnoid hemorrhage in a multimodal approach heavily weighted toward mechanical thrombectomy with Solitaire stent in acute stroke. Stroke 2013;44:414-19 CrossRef Medline

124. Herial N, Qureshi M, Khan A, et al. Arterial reocclusion and distal embolization during endovascular treatment using new generation stent retrievers in acute ischemic stroke patients. Neurology 2015;84(14 Suppl P4):299

125. Janjua N, Alkawi A, Suri MF, et al. Impact of arterial reocclusion and distal fragmentation during thrombolysis among patients with acute ischemic stroke. AJNR Am J Neuroradiol 2008;29:253-58 CrossRef Medline

126. Kerr DM, Fulton RL, Lees KR; VISTA Collaborators. Seven-day NIHSS is a sensitive outcome measure for exploratory clinical trials in acute stroke: evidence from the Virtual International Stroke Trials Archive. Stroke 2012;43:1401-03 CrossRef Medline

127. Sajobi TT, Menon BK, Wang M, et al; ESCAPE Trial Investigators. Early trajectory of stroke severity predicts long-term functional outcomes in ischemic stroke subjects: results from the ESCAPE trial (Endovascular Treatment for Small Core and Anterior Circulation Proximal Occlusion with Emphasis on Minimizing CT to Recanalization Times). Stroke 2017;48:105-10 CrossRef Medline

128. Janssen PM, Visser NA, Dorhout Mees SM, et al. Comparison of telephone and face-to-face assessment of the modified Rankin Scale. Cerebrovasc Dis 2010;29:137-39 CrossRef Medline

129. Muir KW, Ford GA, Messow CM, et al; PISTE Investigators. Endovascular therapy for acute ischaemic stroke: the Pragmatic Ischaemic Stroke Thrombectomy Evaluation (PISTE) randomised, controlled trial. J Neurol Neurosurg Psychiatry 2017;88:38-44 CrossRef Medline

130. Khan M, Goddeau RP Jr, Zhang J, et al. Predictors of outcome following stroke due to isolated M2 occlusions. Cerebrovasc Dis Extra 2014;4:52-60 CrossRef Medline
131. Alonso de Leciñana M, Kawiorski MM, Ximénez-Carrillo Á, et al; Madrid Stroke Network. Mechanical thrombectomy for basilar artery thrombosis: a comparison of outcomes with anterior circulation occlusions. J Neurointerv Surg 2017;9:1173-78 CrossRef Medline

132. Minnerup J, Wersching $\mathrm{H}$, Teuber A, et al; REVASK Investigators. Outcome after thrombectomy and intravenous thrombolysis in patients with acute ischemic stroke: a prospective observational study. Stroke 2016;47:1584-92 CrossRef Medline

133. Nogueira RG, Zaidat OO, Castonguay AC, et al. Rescue thrombectomy in large vessel occlusion strokes leads to better outcomes than intravenous thrombolysis alone: a 'real world' applicability of the recent trials. Interv Neurol 2016;5:101-10 CrossRef Medline

134. Jansen I, Mulder M, Goldhoorn RJ, et al; on behalf of the MRCLEAN-Registry investigators (www.mrclean-trial.org). MR CLEAN registry: a post-trial multicenter registry of intra-arterial treatment for acute ischemic stroke in the Netherlands. In: Proceedings of the International Stroke Conference, February 21-24, 2017; Houston, Texas

135. Direct Transfer to an Endovascular Center Compared to Transfer to the Closest Stroke Center in Acute Stroke Patients with Suspected Large Vessel Occlusion (RACECAT). https://clinicaltrials.gov/ct2/ show/NCT02795962. Accessed April 11, 2017

136. Legal Protections for Peer Review H-375.962: American Medical Association. https://searchpf.ama-assn.org/SearchML/searchDetails. action?uri=\%2FAMADoc\%2FHOD.xml-0-3167.xml. Accessed May 31, 2012

137. The Health Care Quality Improvement Act of 1986 (HCQIA), 42 USC $\$ 11101$ et seq.

138. Suydam S, Liang BA, Anderson S, et al. Patient safety data sharing and protection from legal discovery. In: Henriksen K, Battles JB, Marks ES, Lewin DI, eds. Advances in Patient Safety: From Research to Implementation (Volume 3: Implementation Issues). Advances in Patient Safety. Rockville: Agency for Healthcare Research and Quality, 2005. https://www.ncbi.nlm.nih.gov/books/NBK20558/. Accessed January 20, 2018

139. Willner RB. Health Care Quality Improvement Act (HCQIA) of 1986. What is it? Why was it established? Is it working? http:// www.peerreview.org/articles/HCQIQ.htm. Accessed May 31, 2012

140. H. R. 2-114th Congress: Medicare Access and CHIP Reauthorization Act of 2015. http://www.congress.gov/bill/114th-congress/ house-bill/2. Accessed April 24, 2017

141. Hirsch JA, Harvey HB, Barr RM, et al. Sustainable growth rate repealed, MACRA revealed: historical context and analysis of recent changes in Medicare physician payment methodologies. AJNR Am J Neuroradiol 2016;37:210-14 CrossRef Medline

142. Hirsch JA, Leslie-Mazwi TM, Patel AB, et al. MACRA: background, opportunities and challenges for the neurointerventional specialist. J Neurointerv Surg 2016;8:868-74 CrossRef Medline

143. Berkhemer OA, Jansen IG, Beumer D, et al; MR CLEAN Investigators. Collateral status on baseline computed tomographic angiography and intra-arterial treatment effect in patients with proximal anterior circulation stroke. Stroke 2016;47:768-76 CrossRef Medline

144. Hussein HM, Georgiadis AL, Vazquez G, et al. Occurrence and predictors of futile recanalization following endovascular treatment among patients with acute ischemic stroke: a multicenter study. AJNR Am J Neuroradiol 2010;31:454-58 CrossRef Medline

145. Kim JT, Jahan R, Saver JL; SWIFT Investigators. Impact of glucose on outcomes in patients treated with mechanical thrombectomy: a post hoc analysis of the Solitaire flow restoration with the intention for thrombectomy study. Stroke 2016;47:120-27 CrossRef Medline

146. Institute of Medicine (US) Committee on Quality of Health Care in America; Kohn LT, Corrigan JM, Donaldson MS, editors. To Err is Human: Building a Safer Health System. Washington DC: National Academies Press; 2000 